\title{
Major Characteristics of Southern Ocean Cloud Regimes and Their Effects on the Energy Budget
}

\author{
JOHN M. HAYNES* AND CHRISTIAN JAKOB \\ Monash Weather and Climate, Monash University, Clayton, Victoria, Australia \\ WILLIAM B. RosSOW \\ City College of New York, New York, New York \\ GEORGE TSELIOUDIS \\ NASA Goddard Institute for Space Studies, New York, New York \\ JOSEPHINE BROWN \\ Bureau of Meteorology, Docklands, Victoria, Australia
}

(Manuscript received 3 September 2010, in final form 8 March 2011)

\begin{abstract}
Clouds over the Southern Ocean are often poorly represented by climate models, but they make a significant contribution to the top-of-atmosphere (TOA) radiation balance, particularly in the shortwave portion of the energy spectrum. This study seeks to better quantify the organization and structure of Southern Hemisphere midlatitude clouds by combining measurements from active and passive satellite-based datasets. Geostationary and polarorbiter satellite data from the International Satellite Cloud Climatology Project (ISCCP) are used to quantify largescale, recurring modes of cloudiness, and active observations from CloudSat and Cloud-Aerosol Lidar and Infrared Pathfinder Satellite Observation (CALIPSO) are used to examine vertical structure, radiative heating rates, and precipitation associated with these clouds. It is found that cloud systems are organized into eight distinct regimes and that ISCCP overestimates the midlevel cloudiness of these regimes. All regimes contain a relatively high occurrence of low cloud, with $79 \%$ of all cloud layers observed having tops below $3 \mathrm{~km}$, but multiple-layered clouds systems are present in approximately $34 \%$ of observed cloud profiles. The spatial distribution of regimes varies according to season, with cloud systems being geometrically thicker, on average, during the austral winter. Those regimes found to be most closely associated with midlatitude cyclones produce precipitation the most frequently, although drizzle is extremely common in low-cloud regimes. The regimes associated with cyclones have the highest in-regime shortwave cloud radiative effect at the TOA, but the low-cloud regimes, by virtue of their high frequency of occurrence over the oceans, dominate both TOA and surface shortwave effects in this region as a whole.
\end{abstract}

\section{Introduction}

Clouds are an important component of Earth's hydrologic cycle and have a profound effect on the radiation budget of the planet. The satellite era has allowed us to greatly expand our knowledge of the characteristics of

\footnotetext{
* Current affiliation: Cooperative Institute for Research in the Atmosphere, Colorado State University, Fort Collins, Colorado.

Corresponding author address: Dr. John M. Haynes, CIRA, Colorado State University, Fort Collins, CO 80523.

E-mail: haynes@cira.colostate.edu
}

the cloud systems on Earth, but some regions have been studied more comprehensively than others. In the tropics, for example, clouds have been extensively studied because of their connection with deep convection and tropical cyclones. The clouds populating the Southern Hemisphere midlatitudes have received far less scrutiny, in part because of a lack of in situ observations in this ocean-dominated hemisphere. Yet, there are compelling reasons to better understand the cloud systems that occur over the Southern Ocean.

One reason for the recent increasing interest in Southern Ocean clouds is the mounting evidence that they are poorly represented by climate models. Climate model 
errors in top-of-atmosphere (TOA) fluxes over the Southern Ocean are among the largest anywhere in the world (Trenberth and Fasullo 2010, hereinafter TF10). TF10 analyzed 24 coupled climate models from phase 3 of the Coupled Model Intercomparison Project (CMIP3; Meehl et al. 2007) and demonstrated that large biases exist in model ensemble-mean net TOA flux over the Southern Ocean region. These biases are dominated by shortwave radiation with the ensemble model mean bias exceeding $30 \mathrm{~W} \mathrm{~m}^{-2}$ in some regions (individual model biases can be even greater). The sign of the bias is consistent in at least three-quarters of the ensemble members and indicates too much energy is absorbed by the Southern Ocean-atmosphere system. Comparison with International Satellite Cloud Climatology Project (ISCCP; Rossow and Schiffer 1999) cloud fraction shows a deficit of cloud cover in the CMIP models over the Southern Ocean, suggesting a lack of clouds is at least partially responsible for the TOA shortwave bias. The question of what types of clouds contribute to shortwave reflection over the Southern Ocean is therefore of some significance. It is possible, for example, that given the frequent storminess at these latitudes a lack of frontal clouds (i.e., clouds associated with the ascending portions of midlatitude storm systems) in models, or poor representation of the distribution of water and ice within these clouds, is partially responsible for this error (Marchand et al. 2009; Naud et al. 2010; Wu et al. 2007). A lack of boundary layer clouds, such as stratocumulus, may also have a large contribution (e.g., Walsh et al. 2009). In either case, errors of this type cannot be attributed to specific model deficiencies without highquality observations of vertical cloud structure.

The effect of clouds on shortwave radiation can be quantified in terms of the shortwave cloud radiative effect $\mathrm{CRE}_{\text {Sw, }}$, which is defined as the difference between the net TOA fluxes of solar radiation between clear-sky and all-sky conditions (the longwave cloud radiative effect $\mathrm{CRE}_{\mathrm{LW}}$ is defined similarly). Tsushima et al. (2006) normalized this quantity by the incoming solar radiation, referring to it as the albedo forcing, and showed that the Southern Hemisphere region poleward of $40^{\circ} \mathrm{S}$ has the largest observed values of albedo forcing anywhere between $60^{\circ} \mathrm{N}$ and $60^{\circ} \mathrm{S}$. This indicates that clouds occurring here have a relatively large impact on the TOA shortwave radiation balance (per unit insolation). They also showed that a selection of atmospheric general circulation models participating in the Cloud Feedback Model Intercomparison Project (McAvaney and Le Treut 2003) had the largest intermodel differences of albedo forcing in this region.

Given the relatively large expanse covered by the Southern Ocean, it is reasonable to assume that errors in cloud representation in this area will have a relatively large effect on the global TOA energy balance for solar radiation. The atmospheric heating gradient is also likely misrepresented when cloud cover errors are present. This gradient drives the ocean circulation in atmosphereocean coupled models, and errors here will propagate back into the atmospheric circulation. TF10 showed that among the CMIP models a strong linear relationship exists between the net radiation at the Southern Hemisphere TOA and the climate sensitivity of the models, defined as the change in surface temperature produced by doubling atmospheric carbon dioxide. In particular, models with greater net downward TOA radiation than observed (consistent with deficient total cloud coverage) have the smallest climate sensitivities. Models that more closely reproduce the observed TOA radiation balance, by contrast, have the largest climate sensitivities. This again underscores the importance of correctly representing Southern Ocean clouds in climate models.

To understand and ultimately correct problems with Southern Hemisphere clouds in current-day climate models, we need to better quantify which clouds are present over the Southern Ocean, including their horizontal and vertical distribution, radiative effects, and how they are organized, for example, how the occurrence of various modes of cloudiness relates to midlatitude cyclones, vertical air velocities, and so on. This is especially important for the purposes of model evaluation, since we should not only be satisfied to find that our models can satisfactorily reproduce mean radiative fluxes, but should also require them to produce clouds with the right properties in the correct locations, and for reasons that are physically consistent with what is observed in nature. Since clouds produce precipitation, it is also important to quantify this process. In terms of model evaluation, model errors in precipitation frequency and intensity are often large and can offset each other, effectively masking the problem if only accumulated rainfall is considered (Sun et al. 2006). Brown et al. (2010), for example, demonstrate such errors in precipitation over portions of the Australian continent.

Previous observational studies focusing on Southern Ocean midlatitude cloudiness have focused largely on field campaigns with limited regional applicability. Fitzpatrick and Warren (2007) utilized 11 yr of surface radiation and cloud cover measurements obtained during cruises of the RSV Aurora Australis to develop climatologies of cloud albedo, optical depth, and radiative forcing for the Southern Ocean. The Southern Ocean Cloud Experiment (SOCEX) I and II field campaigns flew instrumented aircraft through clouds off the coast of Tasmania to examine their microphysical structure (Boers and Krummel 1998), and the first Aerosol Characterization Experiment (ACE1) campaign utilized shipborne and aircraft measurements to quantify the role of aerosols in 
boundary layer cloud formation (Bates et al. 1998). Numerous cloud-seeding studies in Tasmania have also yielded limited microphysical details about wintertime clouds in that localized area (e.g., Morrison et al. 2009; Smith et al. 1979); large-scale observational studies of Southern Hemisphere midlatitude clouds are lacking despite the long-term availability of satellite observations, however.

This study brings together some older and newer datasets in a way that caters to the strengths of each, and it uses these data to examine clouds populating the broad region of the Southern Ocean. The techniques used herein utilize both passive and active satellite sensors and can easily be extended to other regions of the globe. First, geostationary and polar-orbiting satellite observations of clouds from the ISCCP (Rossow and Schiffer 1999) are used to find large-scale, repeating cloud features over the Southern Ocean (cloud regimes). Next, measurements from the CloudSat radar (Stephens et al. 2008) and Cloud-Aerosol Lidar and Infrared Pathfinder Satellite Observations (CALIPSO) lidar systems (Winker et al. 2007) are matched to these ISCCP-derived cloud regimes and are utilized to derive detailed vertical cloud structure and precipitation, quantities that are absent from the ISCCP-only perspective. This joint analysis also provides information about how the cloud regimes contribute to the TOA radiation balance and, in particular, the shortwave portion of the spectrum that is so poorly represented in climate models.

The next section describes the datasets used in this study and describes bulk features of Southern Ocean cloudiness acquired from these datasets, including the frequency of cloud ice and liquid, both seasonally and spatially. In section 3, a set of cloud regimes, or reoccurring patterns of cloudiness, are derived from the ISCCP observations for the Southern Ocean, similar to those derived in the tropics by Rossow et al. (2005). The cloud regimes are combined with independently derived dynamical variables such as sea level pressure and thermal advective tendencies to provide some basic insight into the background dynamical states that exist. The contributions of each cloud regime to the TOA radiation balance of the Southern Ocean are then assessed. Section 4 investigates the details of the vertical structure and precipitation characteristics of the cloud regimes using CloudSat and CALIPSO observations, followed by discussion and conclusions in section 5 .

\section{Datasets}

Geostationary and polar-orbiting-based satellite data used in this study have been obtained from ISCCP (Rossow and Schiffer 1999). The ISCCP datasets combine observations from a large array of satellites, each of which observes visible and infrared radiances emitted by Earth's atmosphere, surface, and clouds, spanning multiple years and covering most of Earth's surface. The ISCCP D1 dataset contains 3-hourly, 280-km equal-area gridded data of cloud location, occurrence, and optical properties, and was obtained for July 1983 through June 2008 (ISCCP continues to release newer products). Cloud fraction is provided in bins sorted by cloud-top pressure (seven bins between 30 and $1000 \mathrm{hPa}$ ) and visible optical depth (six bins between 0.02 and approximately 380 ). Since the cloud-top temperature and pressure retrievals use visible radiance to adjust measurements based on infrared emission, only daytime retrievals are used in this study. TOA radiative flux calculations were obtained from the ISCCP Flux Data (ISCCP FD) product (Zhang et al. 2004), which is derived on the same temporal and spatial scales as the D1 product.

The active sensors used in this study are the cloudprofiling radar (CPR) on board CloudSat, and the CloudAerosol Lidar with Orthogonal Polarization (CALIOP) lidar on the CALIPSO satellite. Both are part of the Afternoon Train (A Train), a constellation of four satellites that orbit in formation in a sun-synchronous orbit at approximately $705 \mathrm{~km}$ above mean equatorial sea level, with a repeat cycle of approximately 16 days. The chief benefit of formation flying is that it allows multiple sensors to make near-simultaneous measurements of Earth's atmosphere in both space and time.

The CloudSat CPR (Stephens et al. 2008) is a near-nadirpointing millimeter-wavelength $(94 \mathrm{GHz})$ radar system launched in 2006 that has collected data nearly continuously since June of that year. The radar system is optimized for vertically profiling clouds through the atmosphere and can be used to simultaneously quantify cloud boundaries, microphysical properties, radiative heating, and precipitation characteristics. The radar vertical resolution is $240 \mathrm{~m}$, and the cross-track resolution is approximately $1.4 \mathrm{~km}$ (Tanelli et al. 2008). Cloud boundary and radar reflectivity observations used in this study were obtained from the level-2B geometric profile (2B-GEOPROF) product (Marchand et al. 2008) for June 2006 through February 2008. Radiative heating rates were obtained from the level$2 \mathrm{~B}$ radiative fluxes and heating rate (2B-FLXHR) product (L'Ecuyer et al. 2008), which uses the CloudSat microphysical retrievals as inputs to a broadband, two-stream, plane-parallel, adding and doubling radiative transfer model. Precipitation incidence and intensity is from the level-2C precipitation column (2C-PRECIP-COLUMN) product (Haynes et al. 2009) over the oceans only. Precipitation incidence from CloudSat is derived using an attenuation-based algorithm and has been shown to match ship-based observations of precipitation incidence very well over the midlatitude oceans (Ellis et al. 2009). 
Although CloudSat is able to detect most clouds in the atmosphere, there are two significant limitations: clouds with a small backscatter cross section (chiefly optically thin cirrus) and boundary layer clouds whose presence is made ambiguous by noise associated with strong scattering off Earth's surface (Mace et al. 2009). The CALIOP lidar (Winker et al. 2007) fills in many of these gaps. Owing to its shorter operating wavelength, the lidar is able to detect much smaller cloud particles, and furthermore does not suffer from surface contamination effects. These advantages come with the tradeoff that the lidar attenuates significantly for visible optical depths greater than about 3 , resulting in detection of only the tops of such clouds. Infrequently there may also be some ambiguity between large aerosol particles and cloud drops (Liu et al. 2004). Mace et al. (2009), however, suggest that significantly greater than $90 \%$ of cloud layers are correctly identified as cloud, making the combination of the CPR and CALIOP a robust tool for identifying cloud occurrence. The cloud mask used in this study, therefore, is the merged dataset contained in the 2B-GEOPROF lidar version-4 product (CloudSat-CALIPSO). Cloud is considered to be present anytime the CloudSat radar indicates that hydrometeor exists with high certainty [a cloud-mask value of 30 or greater, corresponding to a false detection rate of approximately $4.3 \%$, as reported by Marchand et al. (2008)], or CALIOP indicates that a given radar range bin contains $50 \%$ or greater cloud cover.

In addition to cloud- and radiation-related variables, this study uses some basic dynamical fields, such as horizontal wind and temperature, to place the cloud observations into the context of the surrounding synoptic-scale flow. These variables are derived from the 6-hourly National Centers for Environmental Prediction-U.S. Department of Energy Atmospheric Model Intercomparison Project Reanalysis, phase 2, dataset (hereinafter NCEP-II), at $2.5^{\circ}$ horizontal resolution on 17 vertical levels (Kanamitsu et al. 2002). In addition, the higher vertical resolution of the European Centre for Medium-Range Weather Forecasts (ECMWF) Re-Analysis (ERA) interim reanalysis (hereinafter ERAInterim; Simmons et al. 2006) is utilized for converting ISCCP cloud-top pressures to cloud-top heights (CTH) (37 vertical levels, $1.5^{\circ}$ horizontal resolution, and 6-hourly time resolution). Vertical temperature structure matched to individual radar range bins is derived from the CloudSat ECMWF auxiliary (ECMWF-AUX) product.

\section{Bulk features of Southern Hemisphere midlatitude cloudiness}

Analysis of both ISCCP and CloudSat-CALIPSO indicates that the Southern Hemisphere belt (SHB, defined in this paper as the region between $30^{\circ}$ and $65^{\circ} \mathrm{S}$ latitude) is among the cloudiest locations on the planet, consistent with other satellite climatologies and ship-based observations (e.g., Warren et al. 1986). The 25-yr area-averaged cloud fraction from ISCCP is 0.79 , and the 3 -yr cloud fraction from CloudSat-CALIPSO is 0.81. Differences in total cloudiness between these datasets are expected for several reasons, primarily because of differences in instrument sensitivity (Rossow and Zhang 2010) but also because of differences in footprint size, cloud discrimination criteria used, and, probably to a lesser extent, the mismatch between the years analyzed. In particular, CALIPSO is more sensitive to thin cirrus than is ISCCP but may overestimate the presence of low cloud (Hagihara et al. 2010). We expect that these sensitivity differences will affect not only the total cloud amount observed in each dataset but also how cloud is partitioned with height.

An ISCCP-style joint histogram (e.g., Jakob and Tselioudis 2003; Rossow and Schiffer 1991; Tselioudis et al. 2000) showing the frequency of occurrence (FOCC) of clouds as a function of both cloud-top pressure and visible optical depth for the SHB during 1983-2008 is given in Fig. 1. According to ISCCP, the most frequently occurring cloud type has a top between 680 and $800 \mathrm{hPa}$ and an optical depth between 3.55 and 9.38. This corresponds to low-to-midclouds of moderate optical thickness. Clouds below $680 \mathrm{hPa}$ account for $35.1 \%$ of total cloudiness over the SHB, consisting mostly of clouds with optical thickness between 1.27 and 9.38.

The annual average distribution of CTH for both the ISCCP and CloudSat-CALIPSO datasets is shown in Fig. 2 (seasonality in the distributions is small and is not shown). For CloudSat-CALIPSO, the cloud-top height of the highest cloud layer is plotted as a dashed line. ISCCP cloud-top pressures have been converted to heights using mean SHB geopotential profiles for the period of 1990-99, as derived from the ERA-Interim reanalysis (we note that performing the height-pressure conversion using the mean geopotential profile at either of the extreme latitudes of the SHB, rather than over the entire belt, vertically shifts the profile in Fig. 2 by at most $0.6 \mathrm{~km}$, or $0.4 \mathrm{~km}$ below $500 \mathrm{hPa}$ ). It is immediately apparent that the way cloud is distributed with height according to each dataset is very different. Although both indicate that the SHB is significantly influenced by lowtopped cloud (low clouds being those occurring in the lowest $3 \mathrm{~km}$ ), the low-level ISCCP peak occurs 1-2 km higher than indicated by CloudSat-CALIPSO. The main differences are in middle levels (clouds occurring between approximately 3 and $7 \mathrm{~km}$ ); although ISCCP indicates there are significant numbers of midlevel cloud tops, CloudSat-CALIPSO shows a bimodal cloud 


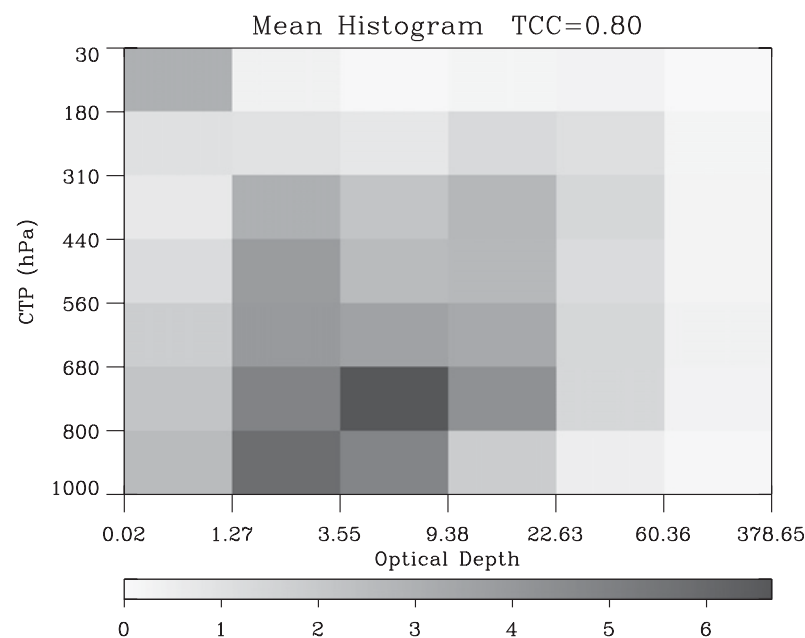

FIG. 1. Mean ISCCP histogram for the SHB between $30^{\circ}$ and $65^{\circ} \mathrm{S}$, showing the frequency of occurrence of cloud (\%) as a function of optical depth and cloud-top pressure, for the period 1983-2008.

distribution consisting primarily of low-topped clouds, with a secondary peak near the tropopause.

There are several reasons for this discrepancy, but the most significant is an inherent limitation in the use of passive measurements to obtain cloud height in multilayer situations, which results in cloud-top misplacement in the ISCCP dataset (Jin and Rossow 1997; Jin et al. 1996; Liao et al. 1995; Mace et al. 2011; Stubenrauch et al. 1999; Tselioudis and Jakob 2002). Whereas CloudSatCALIPSO can observe multiple cloud layers in a single radar pulse without any resulting ambiguity in $\mathrm{CTH}$, the ISCCP algorithm derives CTH primarily from the measured infrared channel emission. When multiple cloud layers are present, particularly optically thin high cloud (with a relatively low emitting temperature) occurring over an optically thick low cloud (with a relatively high emitting temperature), the ISCCP algorithm will interpret this as a cloud with an emitting temperature between that of the two layers and therefore will place the cloud at a corresponding height between the two. This has important implications for the evaluation of numerical models, as will be discussed in section 5 .

To support the assertion that multilayered cloud scenes are responsible for the apparent ISCCP bias toward midlevel clouds, CloudSat-CALIPSO data reveal that $34 \%$ of cloudy scenes over the SHB contained multiple layered clouds (i.e., with layers separated from each other by at least one 240-m-thick radar range gate). The dotted lines in Fig. 2 show the distribution of cloud tops for the lowest layer present in the radar-observed column. Whereas the highest-layer tops exhibit the aforementioned bimodal distribution, the lowest-layer tops heavily favor low-topped clouds, peaking just below $2 \mathrm{~km}$.

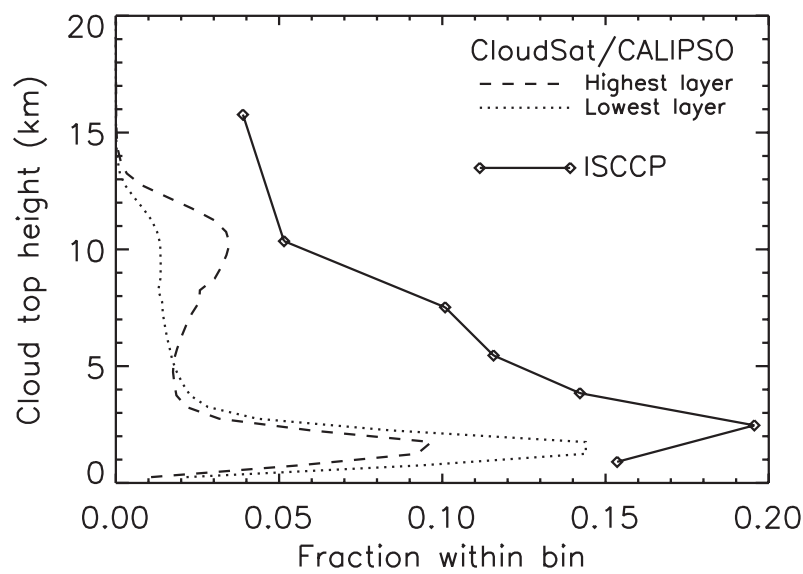

FIG. 2. CTH distributions for the SHB from ISCCP for 1983 2008 (solid line) and from CloudSat-CALIPSO for December 2006-November 2009 (dashed and dotted lines). The dashed line is the CTH of the highest cloud layer observed, and the dotted line is the CTH of the lowest cloud layer. CTH bin sizes are $0.5 \mathrm{~km}$ for CloudSat-CALIPSO and vary as indicated by the diamond symbols for ISCCP.

The difference between the lowest- and highest-layer cloud-top distributions is exclusively caused by the presence of multiple layers, and this suggests that, although most cloud layers occurring over the SHB have tops below $2 \mathrm{~km}$, these clouds frequently coexist with other cloud layers that peak near the midlatitude tropopause at about $10 \mathrm{~km}$.

It is possible to create joint histograms of cloud FOCC from CloudSat-CALIPSO data that are somewhat analogous to the ISCCP-style histogram shown in Fig. 1. CloudSat-CALIPSO profiles were placed into $1.5-\mathrm{km}$ $\mathrm{CTH}$ and geometric thickness bins using two different sets of criteria: 1) the CTH of each individual cloud layer within the profile and the layer's geometric thickness and 2) the CTH of the highest cloud layer in the profile and the total geometric cloud thickness of all cloud layers in the column.

Figure 3 shows these histograms for DJF and JJA; histograms using individual layer thickness are shown in the top row, and those using total layer thickness are shown in the bottom row. Since just over one-third of the profiles observed by CloudSat-CALIPSO contain multiple layers, the sum of FOCC for the histograms in the top row of the figure is greater than unity. The yellow symbols and lines (right axis) show the fraction of radar profiles containing cloud with thickness corresponding to the given $1.5-\mathrm{km}$ bin.

Looking at the top row of histograms formed from individual cloud layers, three dominant modes of cloud occurrence are apparent. First are the low, physically thin clouds located in the lower-left corner of the diagram. 

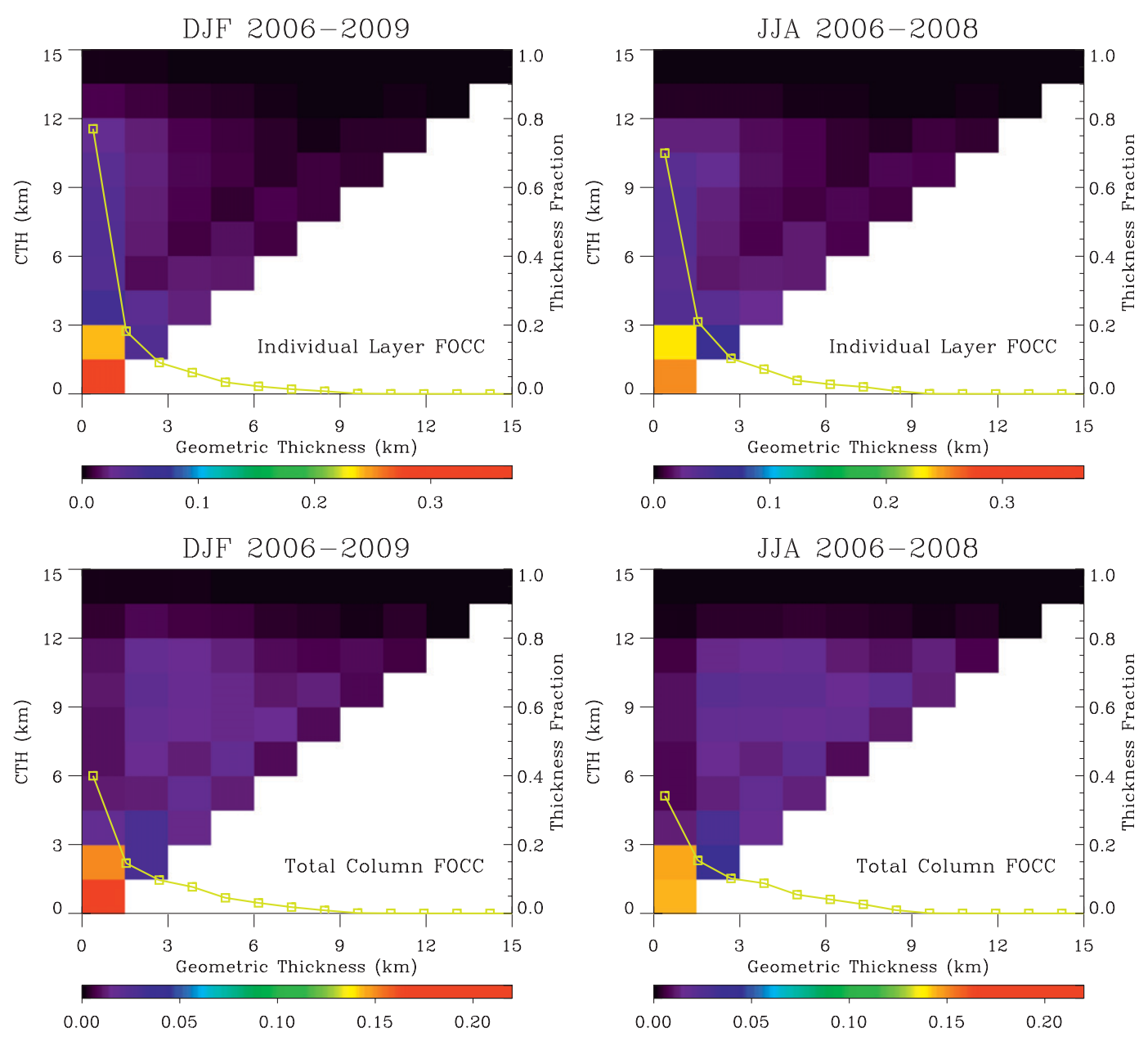

FIG. 3. Histograms of frequency of occurrence of cloud derived from CloudSat-CALIPSO as a function of (top) individual CTH and layer geometric thickness and (bottom) top-layer CTH and total column geometric thickness for (left) DJF 2006-09 and (right) JJA 2006-08. Yellow symbols and lines (right axis) show the fraction of radar profiles containing cloud with thickness corresponding to the given $1.5-\mathrm{km}$ bin.

These are the most frequently occurring cloud type in all seasons. Second are physically thin cloud layers located between approximately 3 and $10 \mathrm{~km}$, and with a nearly equal probability of occurrence anywhere between these levels. These are found along the left edge of the diagram. Third, there is a high frequency of cloud layers that are as high as they are deep, which populate the diagonal of the diagram. Cloud layers with thicknesses up to $1.5 \mathrm{~km}$ count for most clouds observed in the SHB. There is a seasonal shift, with the FOCC of the thinnest cloud layers decreasing during the winter months [June-August (JJA)] while thicker clouds become more frequent. It is presumed that this is associated with increased storm-track activity; this will be discussed further in section 4 . When viewed in terms of total cloud geometric thickness, the relative contribution of the thinnest cloud columns is diminished, as indicated by a shift in the FOCC toward the right side of the diagram.
This shows that the aforementioned thin cloud layers often coexist with clouds at other levels.

To further examine modes of cloud-layer coexistence, joint height-frequency diagrams are provided that show the probability of a CloudSat-CALIPSO-identified cloud occurring at height $L_{b}$ anywhere in a vertical column, given that a cloud is simultaneously observed at height $L_{a}$, for December-February (DJF) 2006-09 and JJA 2006-08 (Fig. 4). The diagonal of this diagram is necessarily unity, and the width of the distribution surrounding this diagonal indicates the degree to which layers at a given height are correlated with nearby cloud layers. Several pieces of information can be gleaned from this figure. First, it is evident that the occurrence of low cloud in the SHB is highly correlated with the occurrence of cloud at all other levels; for example, when a cloud is detected anywhere within the troposphere, the probability of finding low cloud is very high (this is represented by the horizontal 

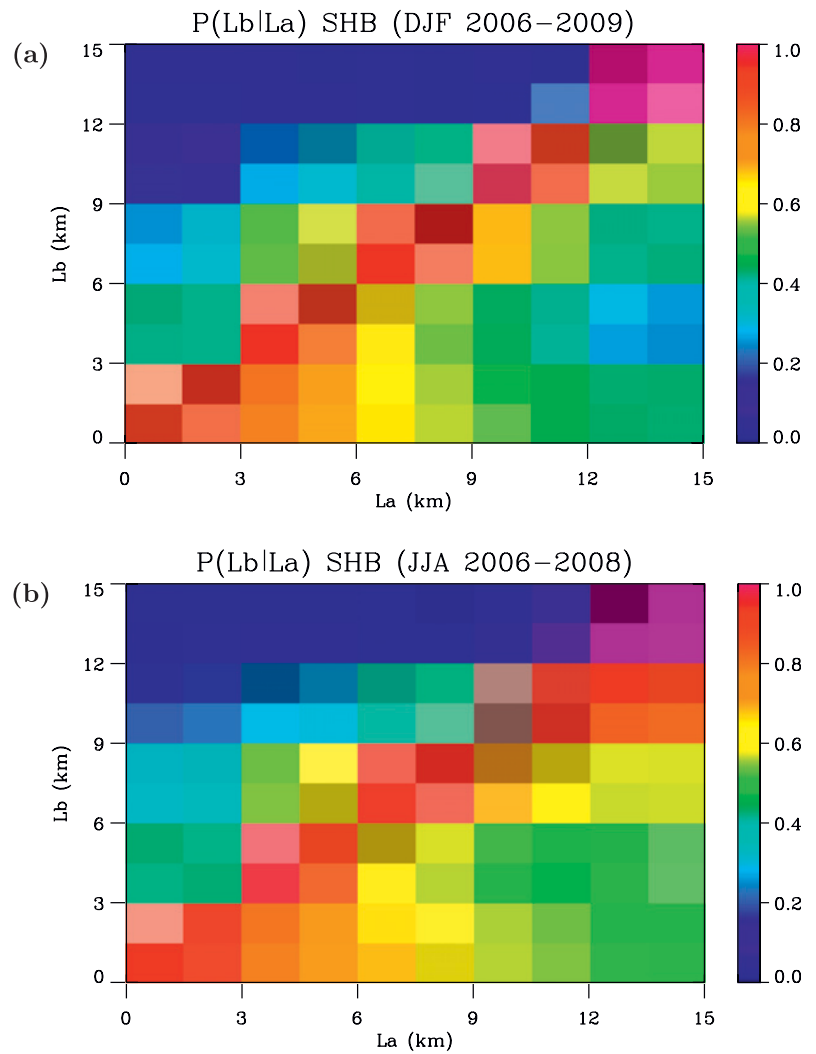

FIG. 4. Joint height-frequency diagrams for the SHB for (a) DJF 2006-09 and (b) JJA 2006-08, showing the probability of a cloud occurring at $L_{b}$ given that a cloud is observed at $L_{a}$.

extension of oranges and reds at the bottom of the diagram). Second, midlevel cloud (between approximately 3 and $7 \mathrm{~km}$ ) has the highest correlation with neighboring cloud layers, suggesting midlevel clouds tend to occur in relatively thick layers. Third, seasonal differences in cloud structure are substantial (e.g., Rossow and Schiffer 1999). Maximum cloud height varies with tropopause depth seasonally, but the occurrence of a mode of cloudiness filling the entire troposphere, visible on the right side of Fig. 4b, is limited to the winter months (JJA) when the storm tracks are most active.

\section{ISCCP cloud regimes and active-sensor subsets}

Although the active and passive sensor views of cloudiness differ, as is to be expected given their different detection capabilities and footprints, they do tell largely the same story on mean cloud structure: the SHB has a relatively high frequency of occurrence of cloud, and most of these clouds occur at low levels. Having established some basic parameters of the clouds that occur over the SHB, it is next instructive to determine how this cloudiness is organized in space and time and how cloudiness is tied to the synoptic-scale flow, for example, the occurrence of midlatitude cyclones. The basis of this analysis is the long-time record ISCCP D1 dataset. A clustering algorithm was used to identify common modes of cloudiness, or cloud regimes. This is a straightforward extension of the methods developed for the tropics by Jakob and Tselioudis (2003) and Rossow et al. (2005). The clustering was applied to the ISCCP data for several reasons: 1) the ISCCP data are available for a 25 -yr period whereas CloudSat-CALIPSO data are only available for the few years since launch, 2) the ISCCP data cover a wider horizontal area, and with greater frequency, than is available from CloudSatCALIPSO, and 3) the cloud structures observed from an ISCCP perspective are more directly comparable to those produced by models on the scale of a GCM grid box. After identifying cloud regimes in the ISCCP data, the finer-scale features of these regimes, including vertical structures and precipitation features that cannot be derived using only ISCCP observations, will be examined in detail using new measurements from CloudSatCALIPSO.

The cluster analysis technique used in this work is the $k$-means (KMEANS) algorithm (Anderberg 1973). The inputs are the set of ISCCP daily-mean cloud fraction histograms for a 20-yr subset of the full data period for all locations falling within the SHB and the desired number of clusters to be located $n$. The algorithm starts with a randomly chosen initial seed for each cluster centroid, calculates the Euclidean distance between each data point (i.e., each of the ISCCP histograms) and each cluster centroid, and assigns each data point to be a member of the cluster with the smallest distance. After the assignment of all data points to one of the $n$ clusters, new cluster centroids are calculated by averaging all cluster members. The process then iterates, starting with this new set of clusters, and continues until the difference between clusters from one iteration to the next becomes vanishingly small (Jakob and Tselioudis 2003). Using a mix of objective and subjective criteria (Rossow et al. 2005), the optimal number of clusters (regimes) representing SHB cloudiness is found to be $n=8$.

Gordon and Norris (2010, hereinafter GN10) recently used a similar technique to analyze midlatitude cloud cover. Our technique varies chiefly in that we use all 42 ISCCP cloud classes (e.g., Jakob and Tselioudis 2003; Jakob et al. 2005; Rossow et al. 2005) and focus exclusively on the Southern Hemisphere. Their differences are not expected to result in significantly different clusters, as suggested by GN10. In fact, we should require the resulting clusters from these two variations on the technique to be similar as an additional form of quality control. We emphasize, however, that, whereas GN10 use the cluster analysis as an organizing principle, 
S1 $\mathrm{TCC}=0.566, \mathrm{FOCC}=0.370$

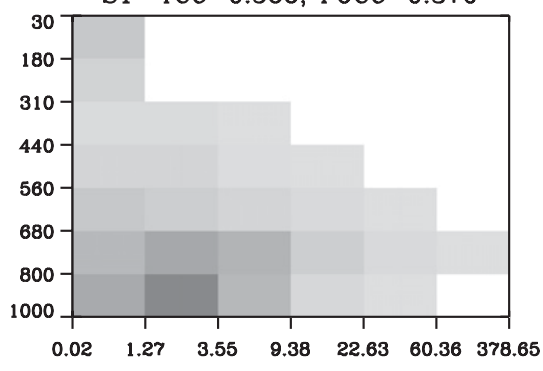

S4 TCC $=0.912$, FOCC $=0.097$

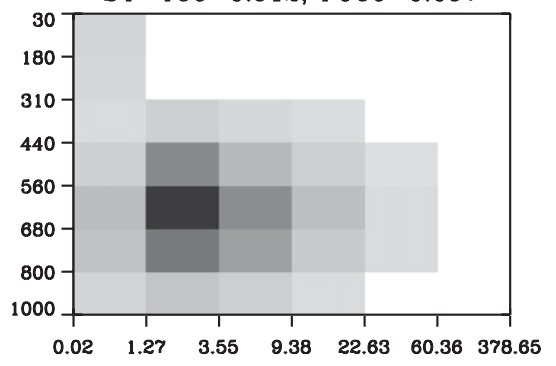

S7 TCC $=0.991$, FOCC $=0.098$

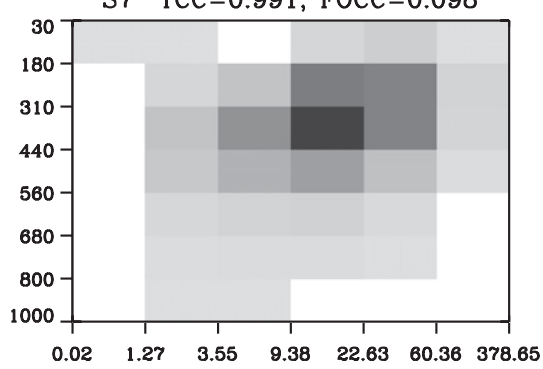

S2 $\mathrm{TCC}=0.871, \mathrm{FOCC}=0.077$

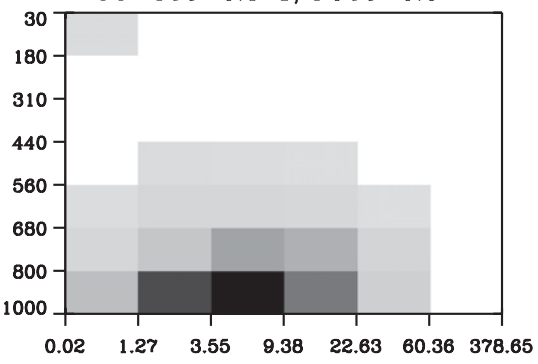

S5 TCC $=0.971$, FOCC $=0.121$

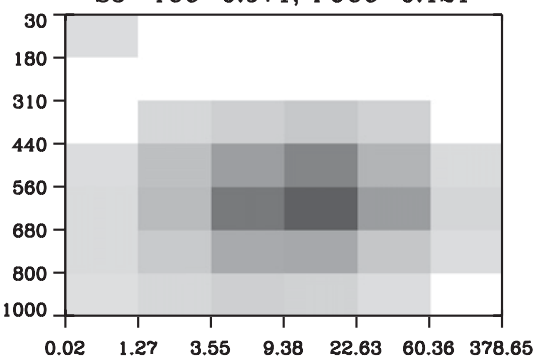

S8 TCC $=0.743$, FOCC $=0.047$

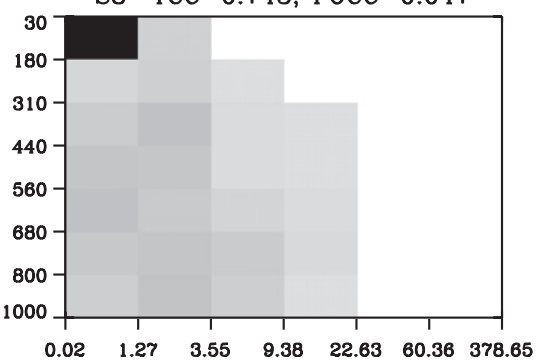

S3 TCC $=0.926$, FOCC $=0.096$

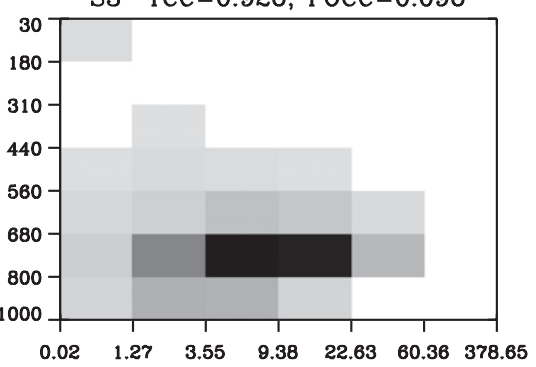

S6 TCC $=0.954$, FOCC $=0.096$

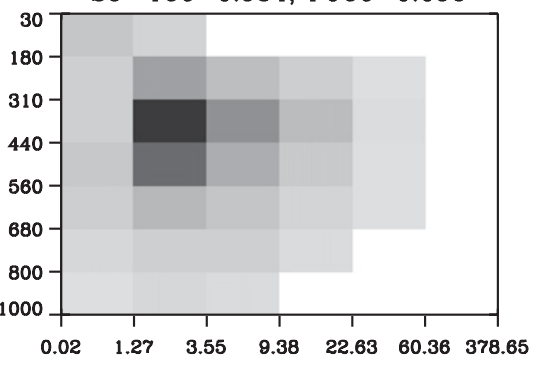

FIG. 5. As in Fig. 1, but for each of the eight derived SHB cloud regimes.

our main goal is to elucidate the cloud properties-and, in particular, the vertical cloud structures and associated radiative properties of the cloud regimes.

The ISCCP histograms of the eight cloud regimes identified as the main components of SHB cloudiness are shown in Fig. 5 (these regimes are available for download through the ISCCP Worldwide Web site). They are labeled S1-S8 and are arranged from lowest to highest cloud top, using optical thickness as a secondary classification for regimes with similar heights. The frequency of occurrence of each regime and the total fractional cloud cover associated with each are also shown in each panel. There are two regimes dominated by very low-topped clouds below $800 \mathrm{hPa}$ (S1 and S2), three with dominant middle-topped clouds between 800 and $440 \mathrm{hPa}$ (S3-S5), and three composed chiefly of high-topped clouds above $440 \mathrm{hPa}$ (S6-S8). The most frequently occurring regime is $\mathrm{S} 1$, with an FOCC of 0.37 , which is dominated by low cloud of relatively low optical thickness. The total fractional cloud cover of this regime is 0.57 . The least frequent regime is S8, with an FOCC of 0.05, which contains high, thin cloud near the tropopause (e.g., thin cirrus). As this is the only regime containing any significant cirrus-type cloud, we again emphasize that lower-level clouds dominate the SHB. The remaining six regimes occur with frequencies between approximately 0.07 and 0.12 and have a high total fractional cloud cover ( 0.87 or greater). S7 is notable in that it contains the highest cloud tops with the highest optical thicknesses, consistent with what might be expected in those "active" portions of midlatitude cyclones associated with storminess (i.e., regions of predominantly ascending air with frequent clouds and precipitation). We note that the regimes are qualitatively very similar to those obtained by GN10 as were derived from cloud observations applied to both midlatitude hemispheres.

The spatial and seasonal distribution of the eight SHB cloud regimes is shown in Fig. 6. The northern SHB is dominated by the low-cloud regime, S1, which occurs considerably more often during the winter (JJA) then summer (DJF) and with greater southward extent during the former. The low-cloud-top, moderate-opticalthickness regime $\mathrm{S} 3$ also exists preferably in the northern 

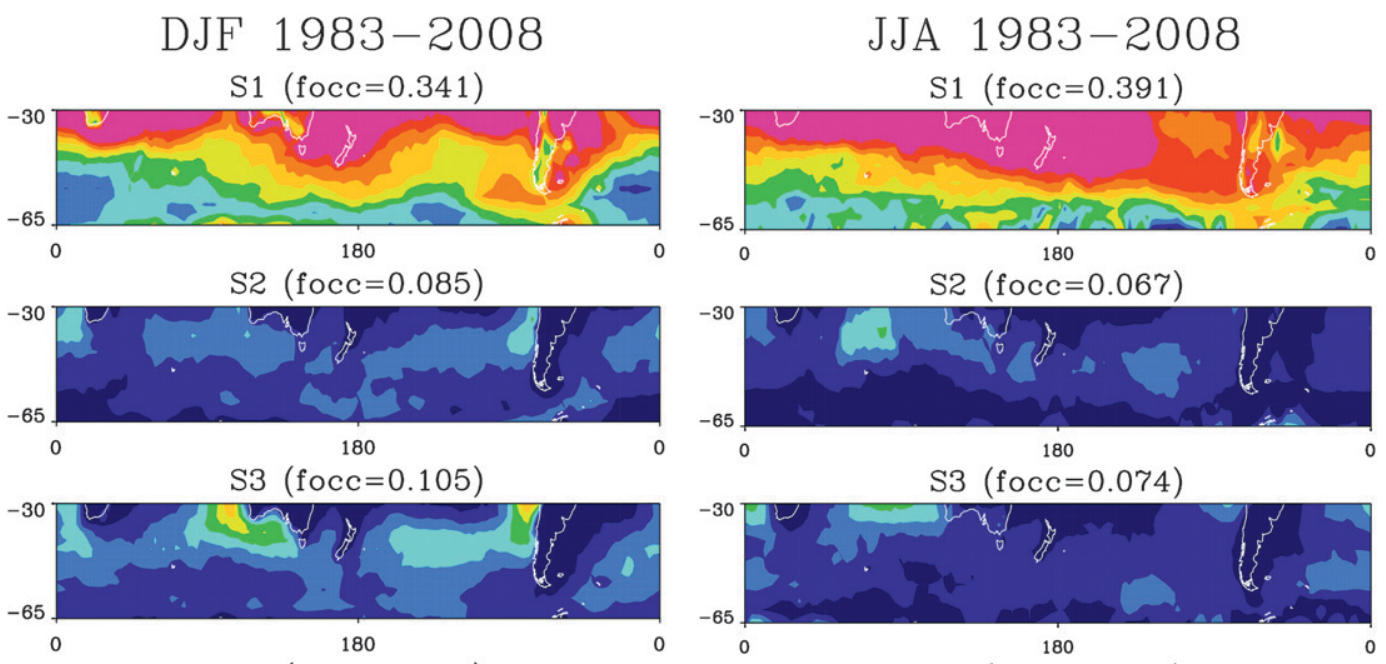

S4 (focc $=0.097)$

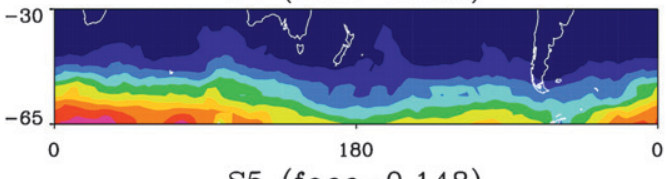

S5 (focc $=0.148)$

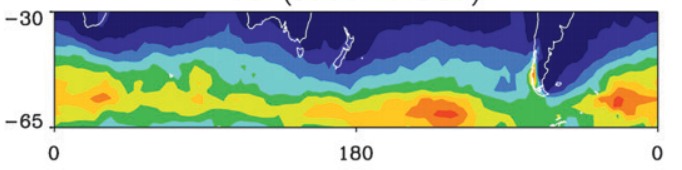

S6 (focc $=0.090)$
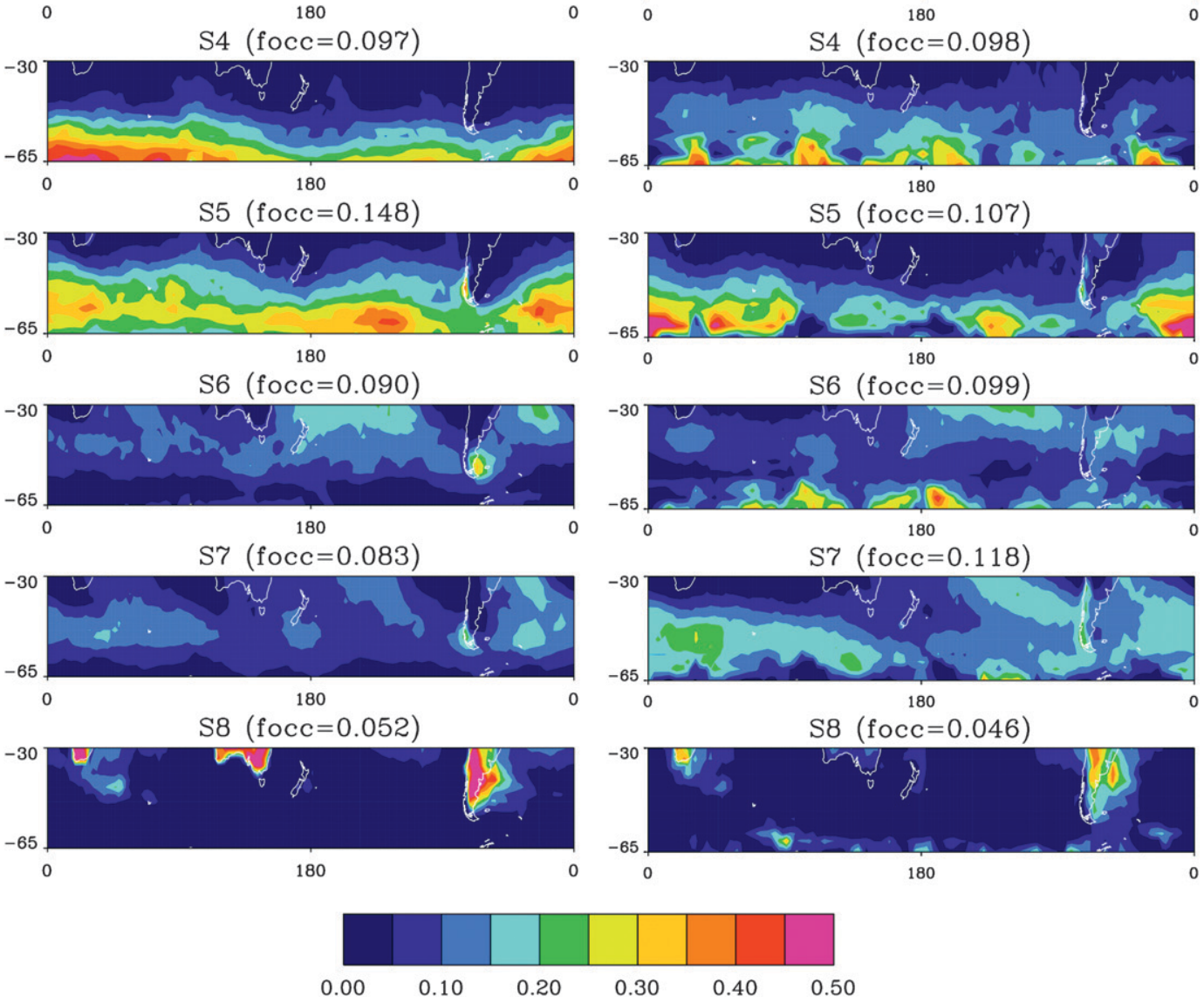

FIG. 6. FOCC of the eight ISCCP-derived cloud regimes for all (left) DJF and (right) JJA months during 1983-2008.

SHB but is more common in summer, especially in the Indian and Pacific Ocean basins. The southern SHB is dominated by what ISCCP identifies as middle-topped cloud regimes, S4 and S5. These regimes are most often found along the circumpolar storm track south of approximately $45^{\circ} \mathrm{S}$. The highest, thickest clouds, S7, occur most frequently during the winter, preferring the South Atlantic Ocean and south Indian basins, with a notably smaller occurrence in the western and central Pacific. These characteristics are consistent with the extratropical cyclone climatology of Simmonds and Keay (2000) and again suggest an association with midlatitude cyclones. Last, we see that S8, the lone regime dominated by cirrus, is almost exclusively found near landmasses, particularly so during the summer months over southern Africa and Australia and east of the Andes Mountains in South 

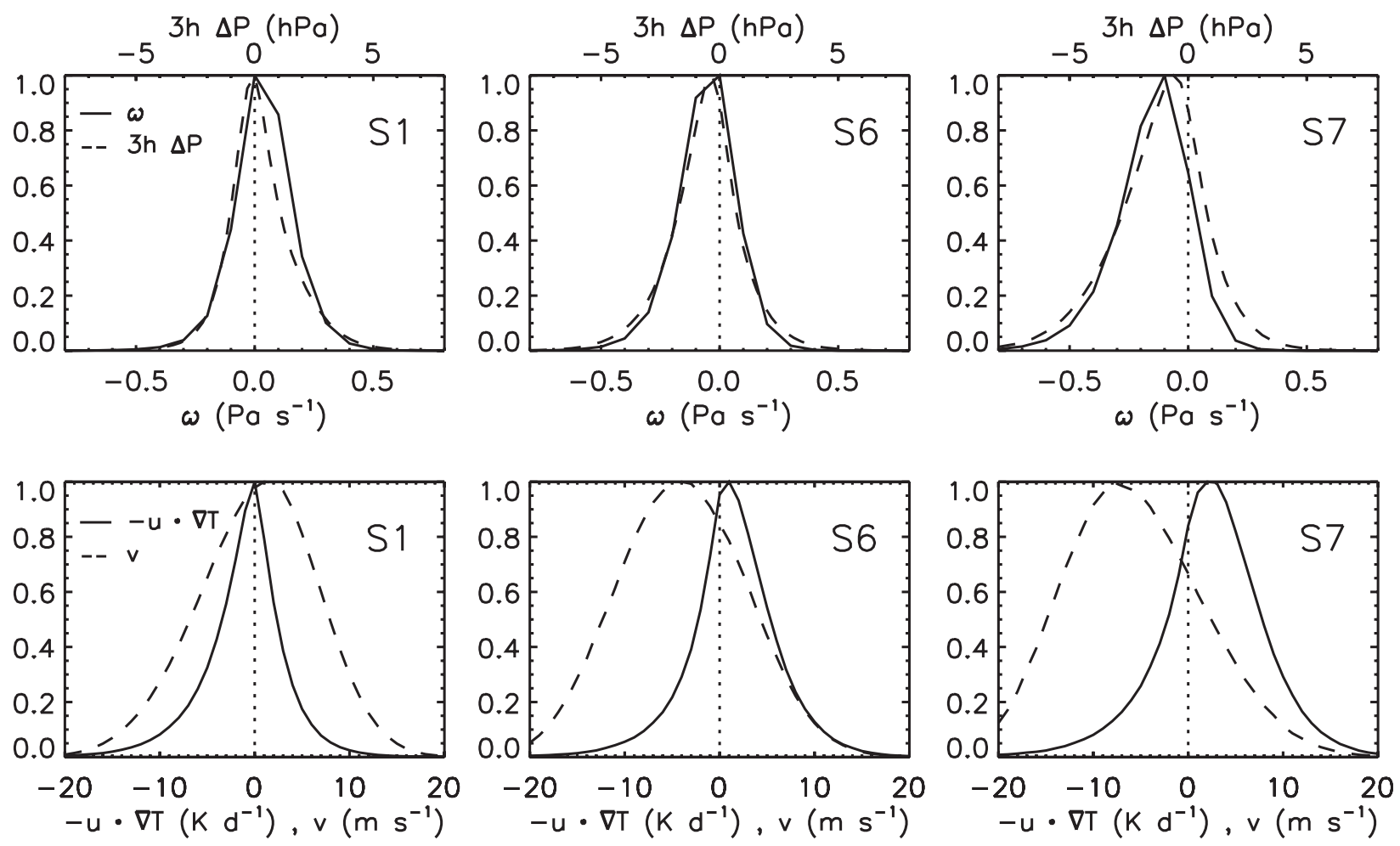

FIG. 7. Histograms of selected quantities derived from the NCEP-II reanalysis matched to regimes S1, S6, and S7: (top) 500-hPa pressure velocity (solid lines) and 3-h mean sea level pressure change (dashed lines) and (bottom) 1000-hPa thermal advection (solid lines) and meridional wind (dashed lines).

America. This regime may be associated with uppertropospheric outflow from convection initiated over the continents, or isolated cirrus generated by orographically forced waves.

\section{a. Dynamical properties}

It is instructive to combine independently derived information about the atmospheric state with the cloud regimes derived from satellite observations, both to ensure physical consistency between the sources of information and to draw new conclusions about the physical context in which each of these regimes occurs. For these purposes, histograms of selected dynamical variables derived from the NCEP-II reanalysis have been derived by matching each daytime ISCCP data point between 1983 and 2008 (determined here on a 3-hourly, rather than daily, basis) to the closest reanalysis variable in space and time. Then all the variables of interest are composited by ISCCP cloud regime. Since GN10 have already demonstrated the utility of sorting cloud regimes by dynamical properties in a general sense, and since our main purpose is to study cloud and radiative properties, results for only three of the most interesting cases-regimes S1, S6, and S7-are shown here to demonstrate the similarity of our regimes to the aforementioned study. Figure 7 shows the resulting distributions of 500-hPa pressure velocity, 3-h mean sea level pressure change, $1000-\mathrm{hPa}$ thermal advection, and $1000-\mathrm{hPa}$ meridional wind.

Regime S7, which we have previously identified as having the highest, deepest clouds, is characterized by midlevel ascent, falling surface pressure, and strong northerly winds with accompanying warm advection at $1000 \mathrm{hPa}$. Each of these properties is consistent with the conditions found in the warm sector of a cyclone (i.e., that part that is pre-cold frontal), strengthening our association of $\mathrm{S} 7$ with the active portions of midlatitude cyclones. Regime S6, which generally occurs farther north than S7, has similar dynamical properties but with means slightly closer to zero. The cloud properties, however, differ: S6 features clouds of top heights similar to S7 but with considerably lower optical thickness. By contrast, S1 (the frequently occurring low-cloud regime), and to a lesser extent S2 and S3 (not shown), are characterized by weak midlevel subsidence, nearly steady or rising surface pressure, and southerly meridional winds at $1000 \mathrm{hPa}$, suggesting these regimes may be associated with more benign, possibly post-cold-frontal, conditions. The presence of low, optically thin cloud in such an air mass is consistent with our knowledge of the structure of midlatitude oceanic cyclones (e.g., Posselt et al. 2008), and 

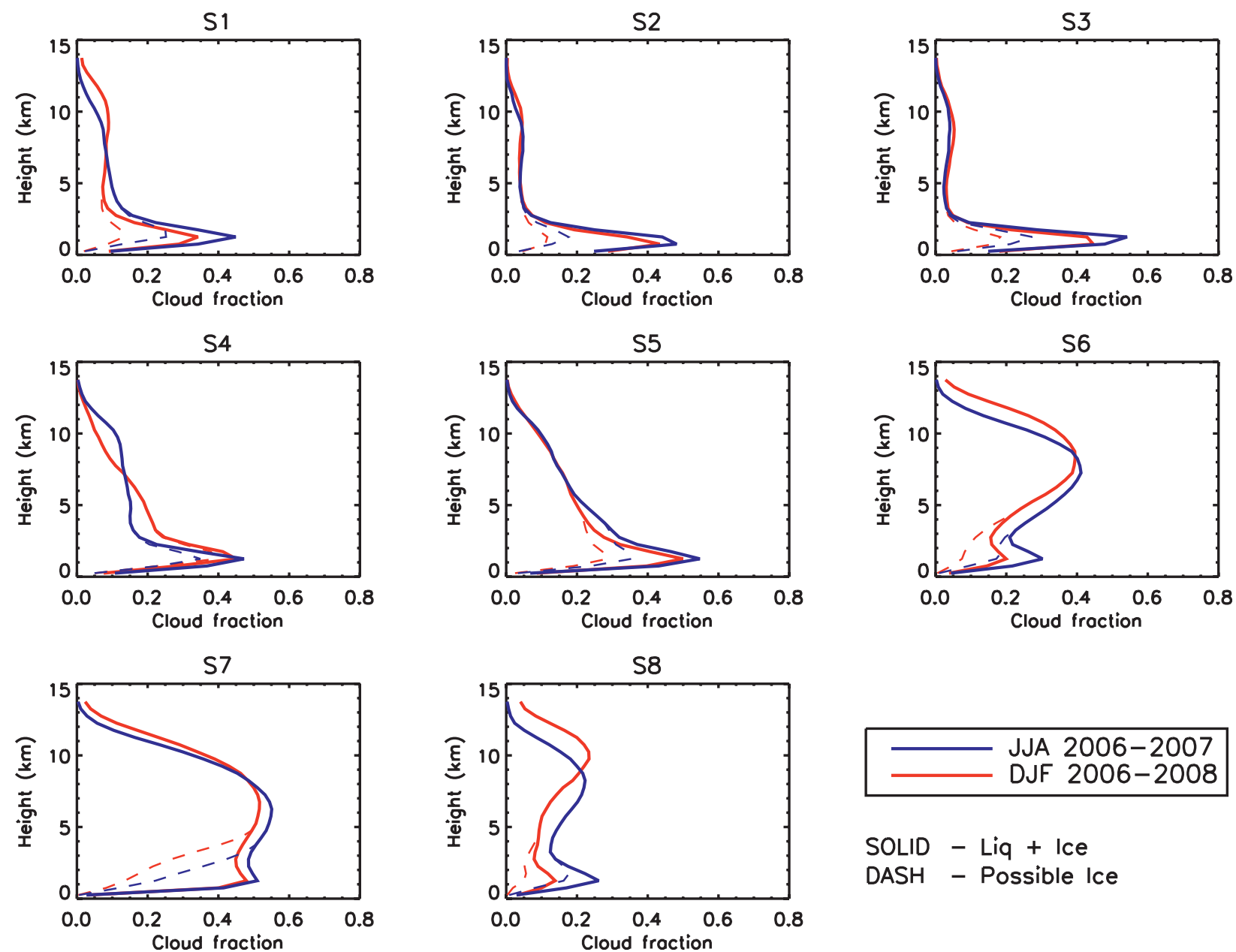

FIG. 8. CloudSat-CALIPSO vertical cloud fraction as a function of height for each of the eight ISCCP cloud regimes for JJA 2006-07 (blue lines) and DJF 2006-08 (red lines). Solid line shows all cloud, and dashed line shows the upper limit on cloud fraction associated with ice or supercooled water.

the occurrence of cold advection over relatively warm SSTs suggests these clouds may be predominantly convective. Naud et al. (2010), using a dynamically based method to locate cyclones and fronts in reanalysis output, also found extensive boundary layer cloud cover in the cold sector of cold-frontal systems.

\section{b. Vertical cloud occurrence}

To examine the vertical cloud structure within the eight ISCCP-based cloud regimes, individual CloudSatCALIPSO profiles from June 2006 to February 2008 were matched in time and space to the nearest ISCCP observation and sorted by cloud regime. Vertical cloud profiles, representing the frequency of cloud cover as it occurs for each regime, are shown in Fig. 8 for the JJA (blue lines) and DJF (red lines) periods. The dashed lines show the occurrence of cloud at a temperature of $0^{\circ} \mathrm{C}$ or lower. This is the maximum possible cloud fraction associated with ice or supercooled water; the actual ice cloud fraction, of course, will often be much lower than the upper limit shown, especially at lower altitudes. To assess the co-occurrence of cloud layers at different heights, a joint height-frequency diagram of CloudSatCALIPSO cloud cover for each cloud regimes is provided in Fig. 9.

Seasonal differences in the distribution of cloud within any given regime are generally very small. This indicates that the basic features of the regimes are largely unchanged throughout the year, even though the frequency of occurrence of a regime at a given location can depend strongly on the season (as demonstrated in Fig. 6). Two exceptions to this are a simple result of a deeper, warmer troposphere during the summer months: the amount of cloud existing as ice and the height at which the cloud fraction maximum occurs in the upper troposphere. The low-cloud regimes, S1-S3, have a low-level cloudiness 

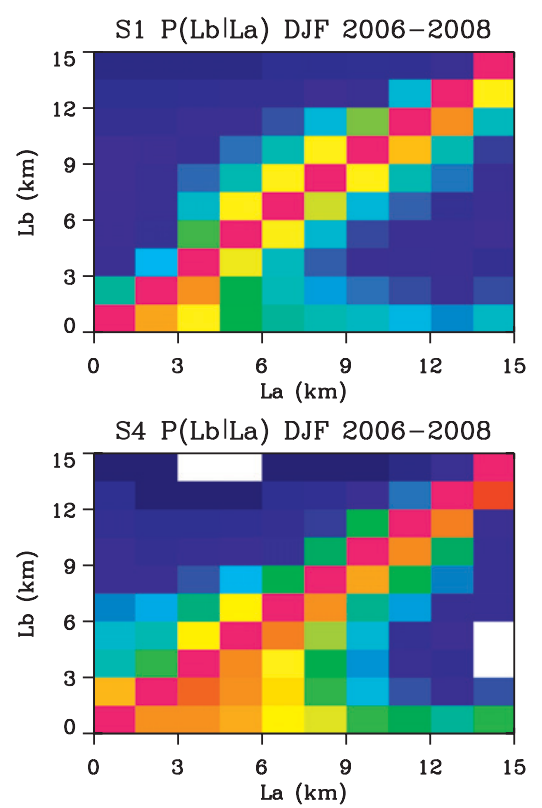

S7 P(Lb|La) DJF 2006-2008

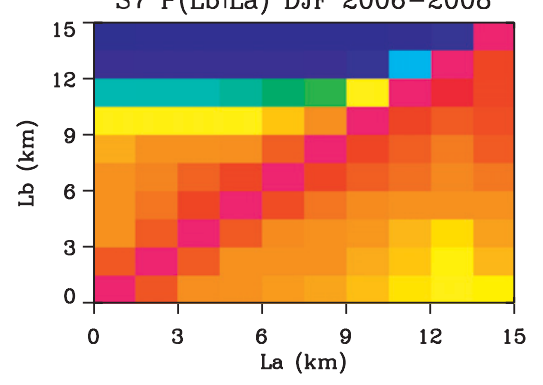

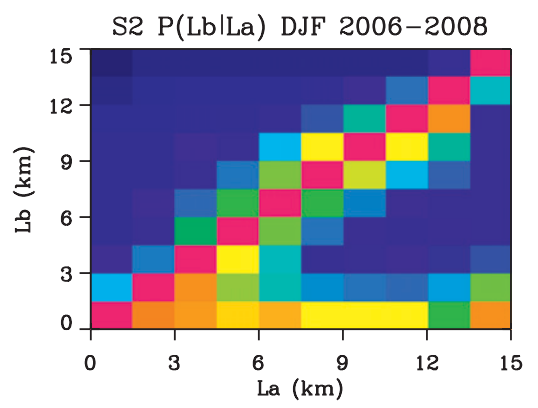

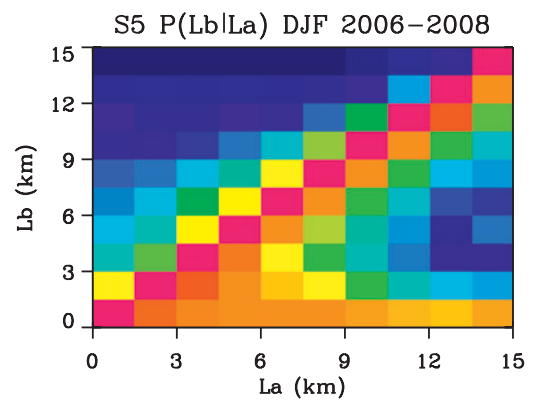

S8 P(Lb/La) DJF 2006-2008

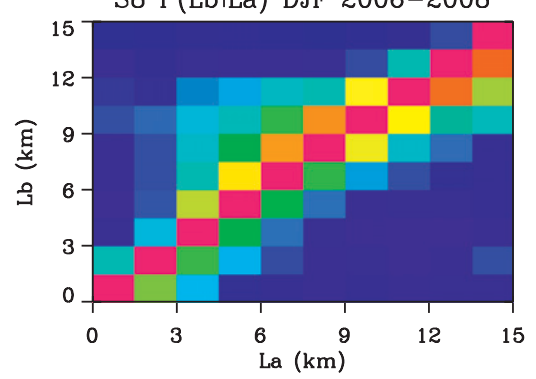

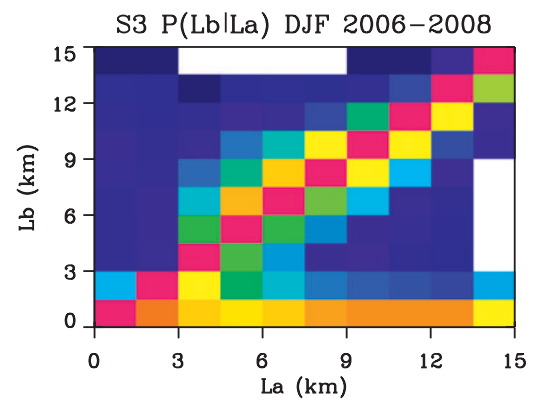

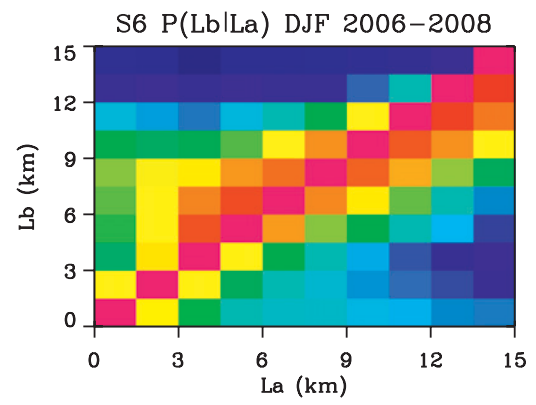

FIG. 9. As in Fig. 4, but for the eight SHB cloud regimes.

peak with a low frequency of midlevel cloud. Regime S1, the dominant cloud regime in the SHB, may contain icephase hydrometeors at low levels at approximately onehalf of the time that cloud is present. Regimes S2 and S3 are very similar except in terms of their potential ice content, which is somewhat larger for S3. It is important to note that the profiles in Fig. 8 do not necessarily represent the most frequent mode of cloud occurrence associated with the various regimes. Consider that S1 contains more midlevel cloud than S2 and S3. Although this is certainly true, the joint height-frequency diagram (Fig. 9) reveals that when cloud occurs in the two lowest bins for regime $\mathrm{S} 1$ (below $3 \mathrm{~km}$ ), the probability of finding a cloud in any given height bin above $3 \mathrm{~km}$ never exceeds $28 \%$. When midlevel cloud does occur in S1, the probability of finding low cloud in the same radar profile is smaller than it is for either S2 or S3. This reveals that S1 contains something of a mix of largely independently occurring cloud layers (though this collection is still dominated by low clouds).

Consistent with the findings described in section 3, CloudSat-CALIPSO finds that those regimes that ISCCP identifies as being dominated by clouds with midlevel tops (S4 and S5) are actually dominated by low cloud but with a significant mid-to-upper-level cloud presence. ISCCP indicates that S5 has similar cloud tops to S4 but with a larger optical thickness. The joint height-frequency diagram supports this to the extent that when midlevel clouds occur, they are more likely to co-occur with underlying cloud (i.e., have a greater physical total thickness) for S5 than for S4. It also indicates that cloud layers at any height occur more than one-half of the time with a coexisting cloud layer below $1.5 \mathrm{~km}$, however. In short, regimes S4 and S5 contain a mix of low- and high-cloud layers, often occurring at the same time, and this configuration is interpreted by ISCCP as a middle-topped cloud scene. This constitutes an important finding, as many cloud evaluations studies based on ISCCP data (e.g., Zhang et al. 2005; Williams and Tselioudis 2007) have noted that GCMs tend to produce too little midlevel cloud. Our results indicate that a more comprehensive analysis of modeled cloud fields is warranted, and that this analysis should include observations with detailed vertical 
structure information such as that provided by CloudSatCALIPSO.

Applying the CloudSat-CALIPSO data to cloud regimes S6 and S7 confirms their classification as high-top, deep-cloud regimes, with S7 containing clouds that extend through the depth of the entire troposphere. Regime S6, however, contains two distinct modes. The first is a mid-to-high-cloud peak at approximately $8 \mathrm{~km}$, which often occurs in relatively thick (several kilometers deep) layers with relatively scant cloud cover in the boundary layer. The second is a low-cloud mode that frequently extends to, or otherwise coexists with, clouds at higher levels. Last, S8, which ISCCP indicates contains the highest, optically thinnest clouds, is found to have relatively small correlations between clouds at different levels, except that mid-to-high-level clouds are sometimes found to occur in relatively thick layer in the upper troposphere. CloudSat-CALIPSO observations indicate that the upperlevel peak in cloud fraction is higher by approximately $2 \mathrm{~km}$ during the summer (DJF), and this is consistent with a higher level of convective storm detrainment with a higher summertime tropopause.

\section{c. Microphysics and precipitation}

Although this study does not seek to specifically quantify the microphysical properties of clouds in the SHB [for a detailed treatment of this, see Mace et al. (2011)], we can make some inferences about the types of hydrometeors populating each regime by examining the distribution of radar reflectivity factor (hereinafter radar reflectivity) with height. Figure 10 shows reflectivityaltitude histograms (RAHs) for CloudSat profiles collected during the two DJF periods starting in 2006 and ending in 2008, sorted according to the closest 3-hourly SHB cloud regime. The diagrams are formed by contouring the counts of radar reflectivity (in $2-\mathrm{dB}$ bins), corrected for gaseous attenuation, as a of function of altitude (in $0.5-\mathrm{km}$ bins). Hydrometeors observed by the lidar, but not by the radar, are not included in these diagrams, so very tenuous clouds and clouds near Earth's surface that CloudSat cannot distinguish from clutter are not represented. In general, points farther to the right on a RAH diagram represent particle distributions containing progressively larger particles. This is because in the Rayleigh backscatter regime, radar reflectivity is proportional to the sixth power of diameter. This applies to most cloud particles at the CloudSat radar wavelength. Although the sixth-power relation breaks down when precipitation or large ice crystals are present, the qualitative interpretation of the RAH diagrams is unchanged.

The low-cloud-dominated regimes $\mathrm{S} 1-\mathrm{S} 3$ are found to contain mostly small hydrometeors below $3 \mathrm{~km}$. S1 is notable in that its distribution is skewed toward somewhat smaller reflectivities, indicating it contains smaller particles or has a larger potential ice content (as suggested by Fig. 8). This regime also contains more high clouds than either S2 or S3. Regimes S4 and S5 are also dominated by small cloud particles at low altitudes but with a greater number of mid- and upper-level clouds with reflectivities between approximately -27 and $-22 \mathrm{dBZ}$. These regimes also have a larger reflectivity variance in the lowest bins when compared with S1-S3. The presence of some returns higher than $0 \mathrm{~dB} Z$, especially in the case of S5 and S7, indicates a high likelihood that some of their constituent clouds are producing precipitation (discussed below). Regime S7, which we have argued is associated with the broad-scale ascent in the warm sector of midlatitude storms, is characterized by relatively large particles with radar echo extending to the tropopause. Regime S6, by contrast, is composed of mostly mid- and upper-level clouds with a broad range of attendant particle sizes.

The precipitation incidence of each of the regimes is evaluated using the attenuation-based CloudSat precipitation retrieval product over oceans only (this introduces minimal bias since less than $3 \%$ of the SHB area is a land surface). Although the CloudSat radar's high sensitivity makes it an excellent detector of precipitation (Ellis et al. 2009), quantification of instantaneous rain rates $R$ is more problematic and is therefore attempted here in only broad rate categories (Haynes et al. 2009). Each radar profile collected during both DJF 2006-08 and JJA 2006/07 is classified into one of seven categories. The first category is no precipitation detected. Three categories are used for rain: $R<1 \mathrm{~mm} \mathrm{~h}^{-1}$, $1 \leq R<5 \mathrm{~mm} \mathrm{~h}^{-1}$, and $R \geq 5 \mathrm{~mm} \mathrm{~h}^{-1}$. For precipitation that may contain a frozen component (as determined from a matched ECMWF temperature profile), precipitation is categorized as either a mix but more likely rain $(\mathrm{mix} / R)$ or more likely snow $(\mathrm{mix} / S)$. Precipitation that is classified as definitely frozen is assigned to the snow category.

Figure 11 shows the seasonal occurrence of precipitation subdivided by these groups as well as regime. Precipitation occurs with an FOCC of 0.16 during DJF and 0.22 during JJA. The regime most likely to produce precipitation, and with the highest incidence of rain heavier than $5 \mathrm{~mm} \mathrm{~h}^{-1}$, is S7. This, unsurprisingly, suggests that the active portions of midlatitude cyclones are the most important source of precipitation over the SHB. Regime S5 is also a significant contributor to precipitation, and because it most frequently occurs over the southern SHB, much of this falls in the snow and the mix/S categories. During the winter, S1, the most frequently occurring low-cloud regime, also produces frequent precipitation. Most of this falls at a rate of $1 \mathrm{~mm} \mathrm{~h}^{-1}$ or less 

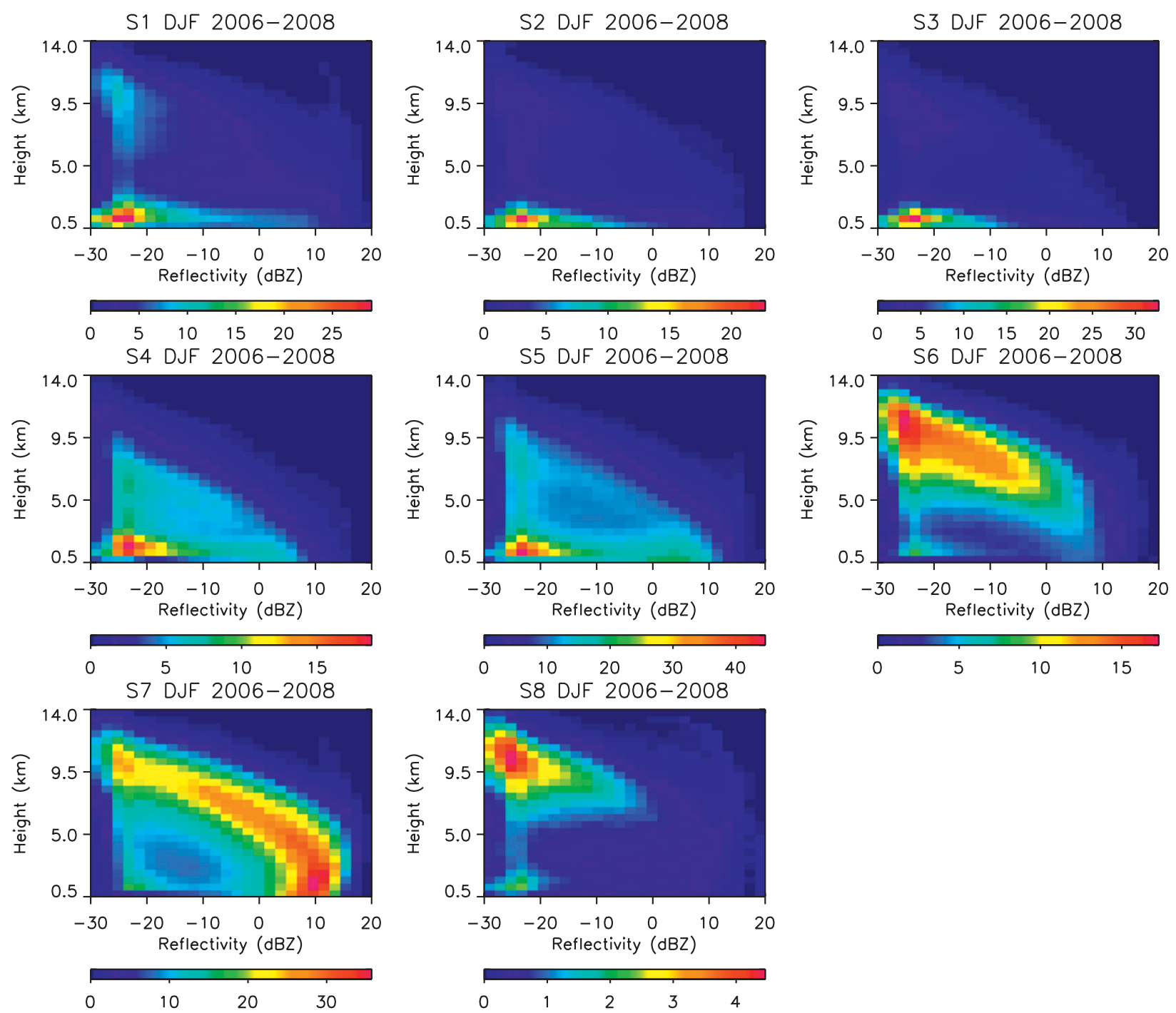

FIG. 10. RAHs for the SHB, DJF 2006-08. Bin count is contoured as a function of CloudSat radar reflectivity (corrected for gaseous attenuation) and altitude.

(drizzle) and especially at higher latitudes as mixed precipitation that is more likely to be snow than rain. Regime $\mathrm{S} 1$ is approximately 2.8 times as likely to precipitate during the winter as during the summer, although it only occurs $33 \%$ more frequently. This may be because the precipitating clouds are deeper during the winter than the summer or because they contain more ice (or supercooled water) and therefore follow different microphysical pathways to precipitation production.

\section{d. Radiative heating and TOA cloud radiative effects}

To assess the radiative heating characteristics of each cloud regime, CloudSat radiative heating profiles, based on the particle distributions described in section $4 \mathrm{c}$, were averaged over swaths of approximately the same size as an ISCCP equal-area grid box. These mean profiles were then assigned to the dominant regime within each swath and averaged together to produce the profiles shown in Fig. 12. Note that the amount of insolation varies dramatically at these latitudes between the winter and summer months (given by the blue and red lines, respectively). The solid lines show net radiative heating, the right set of dotted lines show shortwave heating, and the left set of dotted lines show longwave heating (which is usually negative, representing cooling). The radiative heating associated with regimes S1-S5, which account for $76 \%$ of the annual regime occurrence in the SHB, is dominated by low-cloud effects, mainly composed of cloud-top cooling and cloud-base warming. Cooling is maximum at approximately $2 \mathrm{~km}$ while the heating peaks about $1 \mathrm{~km}$ lower. The cloud-base warming effect tends to be greatest during JJA, when the ocean surface 

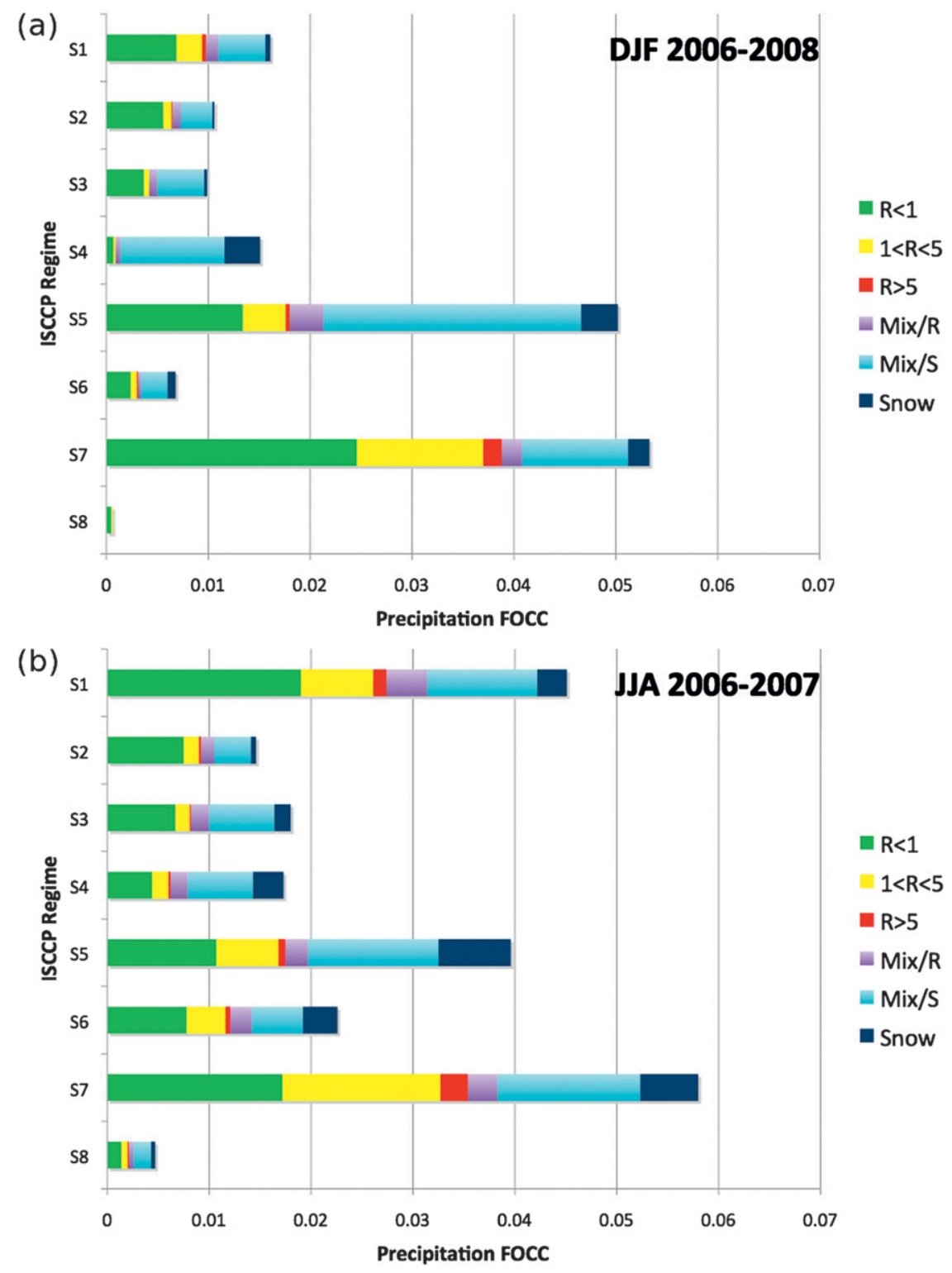

FIG. 11. Precipitation FOCC for each ISCCP cluster for (a) DJF 2006-08 and (b) JJA 2006-07, binned according to the precipitation categories identified in the text.

is, on average, several degrees Celsius warmer than the boundary layer. Cloud-top cooling is also largest during JJA, which is consistent with a cooler overlying atmosphere and lower upper-level cloud coverage during the winter (not shown). The deeper cloud regimes S6 and S7 have mid-to-upper-tropospheric shortwave and longwave radiative heating peaks, the net effect of which depends largely on the season. Although this midlevel heating can be significant, especially during DJF, the higher frequency of occurrence of the lower cloud regimes dominates the SHB. If the frequency of occurrence and/ or microphysical properties of the ubiquitous low-level cloud modes are not well represented by climate models, these low-level heating and cooling peaks are likely to be missing as well. It is interesting to note that in DJF the cloud-top cooling in the low-cloud regimes is largely balanced by solar heating whereas in JJA there is net cooling at the cloud top that must be compensated by other processes; one can speculate, for example, that winter clouds might contain more vigorous turbulence because of the larger gradient in vertical heating. The deeper cloud regimes (S6 and S7) also show a significant summer-winter difference with net midtropospheric heating because of solar effects in summer and net cooling in winter. The effect of these differences on the dynamics of the baroclinic systems in which these 

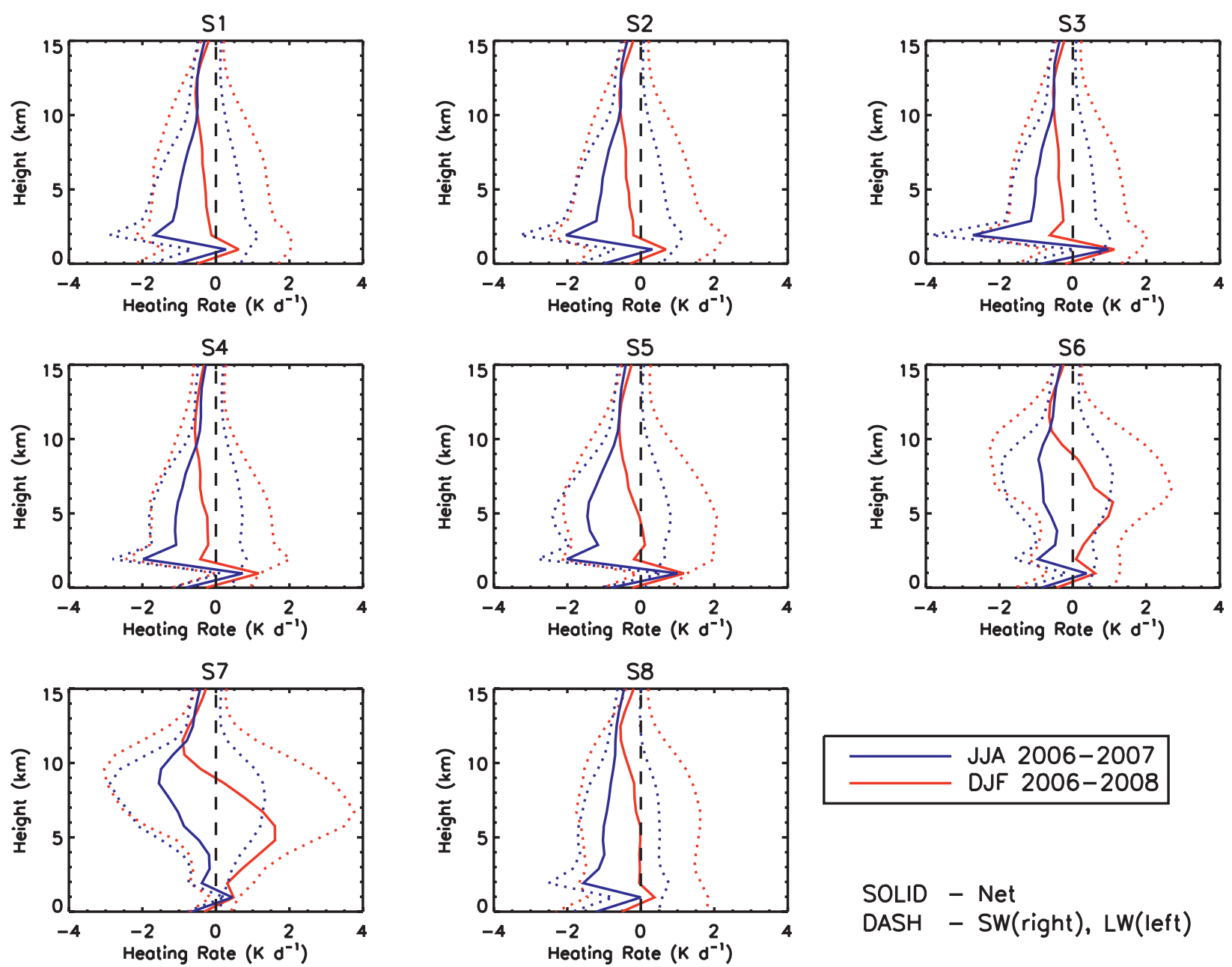

SOLID - Net

DASH - SW(right), LW(left)

FIG. 12. CPR mean radiative heating rate profiles for each of the eight ISCCP cloud regimes for JJA 2006 (blue lines) and DJF 2006/07 (red lines). Solid line shows net heating, left dotted lines (i.e., those that are primarily cooling) show longwave profiles, and right dotted lines (i.e., those that are primarily warming) show shortwave profiles.

clouds are embedded is an interesting subject for further study.

An important quantity for the overall heat balance of the planet is the TOA net radiation. As alluded to earlier, contemporary GCMs have difficulty in simulating this balance correctly over the SHB, with implications for the model's climate sensitivity (e.g., TF10). To evaluate the effects of the various cloud regimes on TOA energy balance, the per-regime seasonal CRE was calculated from the ISCCP FD dataset for DJF and JJA, 1983-2007. Differentiating the contributions by the various regimes is a key way to understand how the mode of cloud organization contributes to the overall TOA energy balance.

The per-event TOA CRE, divided into shortwave and longwave components, is shown in Fig. 13. In the shortwave portion of the spectrum, the high wintertime mean solar zenith angle dominates interseasonal variance, resulting in median shortwave CREs for each regime that are smaller by a factor of 3-4 in absolute value for JJA than for DJF. For DJF, the regime with the smallest (i.e., least negative) $\mathrm{CRE}_{\mathrm{SW}}$ is $\mathrm{S} 8$, the cirrus regime, suggesting that these clouds do not have a particularly high albedo, consistent with their ISCCP classification. The next smallest $\mathrm{CRE}_{\mathrm{SW}}$ is found in the low-cloud regime S1. It is noteworthy that, although it is the most commonly occurring regime, $\mathrm{S} 1$ shortwave $\mathrm{CRE}$ is relatively small. The regime with the largest-magnitude $\mathrm{CRE}_{\mathrm{Sw}}$ is $\mathrm{S} 7$, which was shown to contain the active portions of midlatitude cyclones, featuring both optically and physically thick clouds. Regime S5 is also a significant contributor to $\mathrm{CRE}_{\mathrm{SW}}$.

In the longwave, the lower, optically thinner cloud regimes (S1-S4) have smaller CREs than do the higher, thicker regimes (S5-S7), a consequence of the lower effective emitting temperature associated with the higher 
(a)

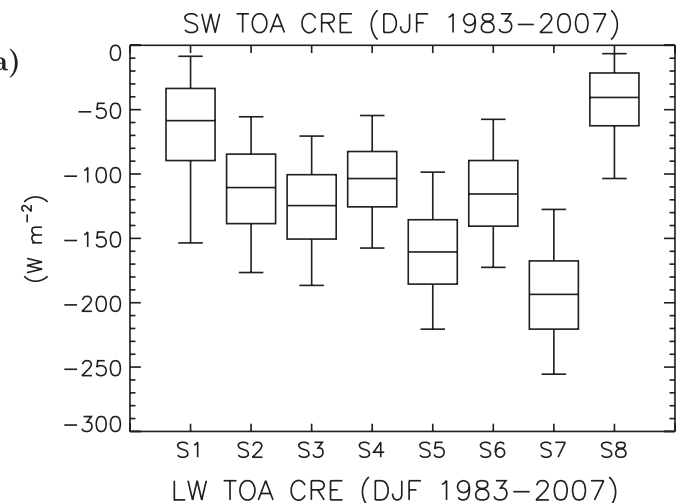

(b)

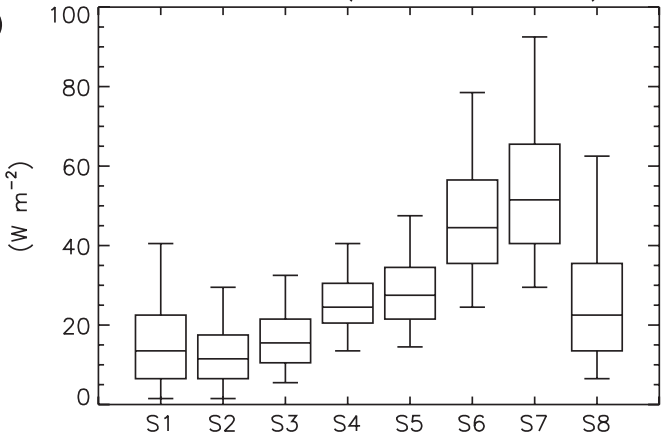

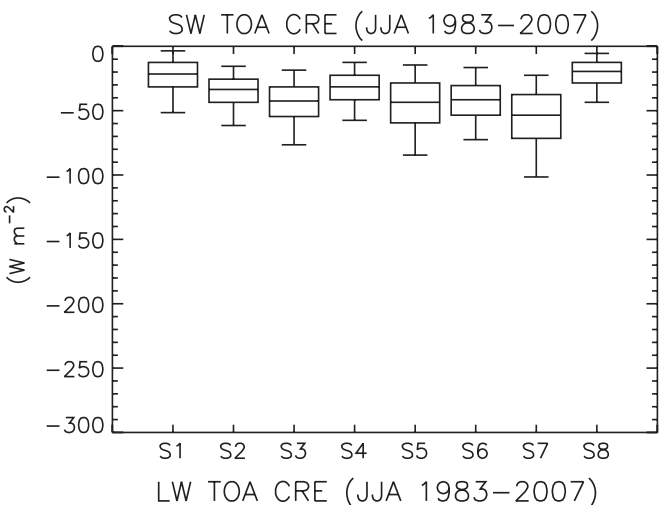

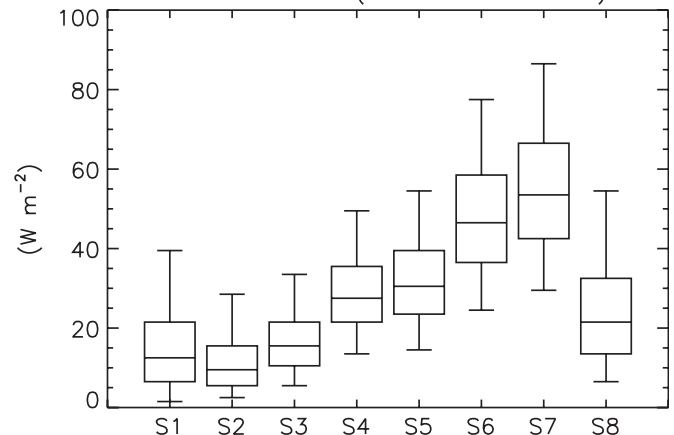

FIG. 13. TOA (a) shortwave and (b) longwave cloud radiative effects for 1983-2007 for all (left) DJF and (right) JJA months, as derived from ISCCP for each cloud regime.

cloud layers. The cirrus regime, $\mathrm{S} 8$, however, is a highcloud regime with relative low $\mathrm{CRE}_{\mathrm{LW}}$ (most likely because these clouds are high but thin, allowing radiation from lower levels in the atmosphere to be transmitted through). Seasonal differences in median $\mathrm{CRE}_{\mathrm{LW}}$ are small, at most $2 \mathrm{~W} \mathrm{~m}^{-2}$.

When the per-regime CRE is weighted by the frequency of occurrence of the regime, the contribution of each regime to the overall SHB CRE can be evaluated. These contributions averaged over the entire SHB region for the 1983-2007 period are shown in Fig. 14. It is evident that the shortwave cloud effects in the SHB are more significant than longwave effects, being greater in magnitude in summer than in winter by a factor of approximately 4.5. These results agree well with the cloud radiative effects evaluated from Earth Radiation Budget Experiment data by Harrison et al. (1990). Focusing on DJF, when shortwave cloud effects are largest, the two most significant contributors to shortwave CRE are regimes S1 and S5. Regime S1 is the dominant low-cloud mode in the SHB, and, while S5 also contains mostly low cloud, it is more likely to coexist with an overlying mid-toupper-level cloud layer; these two regimes also tend to occur in distinct but largely complementary geographic areas (Fig. 6). The midlatitude cyclone regime S7 contributes the third most to shortwave CRE, but, when compared with the accumulated effects of the three low-cloud-dominated regimes $\left(-45.4 \mathrm{~W} \mathrm{~m}^{-2}\right)$, these results suggest that low clouds, and not the active portions of midlatitude cyclones, contribute the most to the shortwave $\mathrm{CRE}$ of the $\mathrm{SHB}$.

\section{Discussion and conclusions}

Motivated by recent findings on the importance of Southern Hemisphere cloudiness for climate sensitivity and the poor simulation of these clouds in climate models, this study uses a combination of passive and active satellite measurements to examine the cloud systems populating the primarily oceanic midlatitude belt of the Southern Hemisphere. Multiple datasets are combined in a way that takes advantage of the strengths of each; ISCCP observations are used for their continuous high spatial and temporal coverage, and CloudSat-CALIPSO observations are used to illuminate the vertical structure of the clouds as well as the occurrence of precipitation. Combining these datasets allows for the development of a long-time-period climatology that includes information about cloud vertical structure and the simultaneous occurrence of multiple cloud layers.

Using cluster analysis based on ISCCP observations, it is found that SHB clouds are organized into eight distinct regimes. Bulk dynamical properties of the regimes from matched reanalysis suggest certain regimes 
(a)
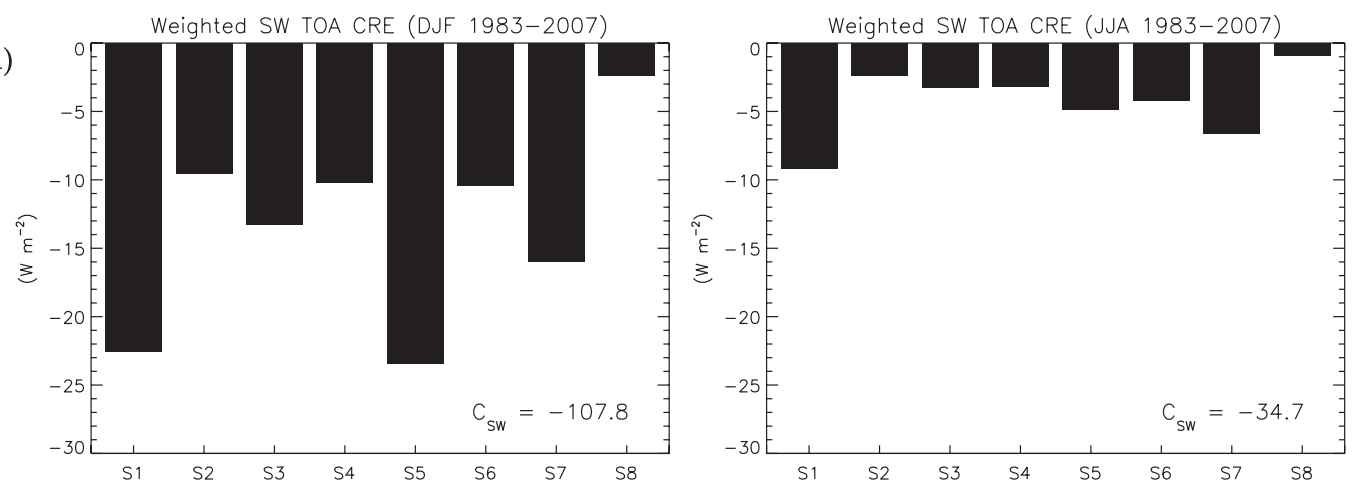

(b)
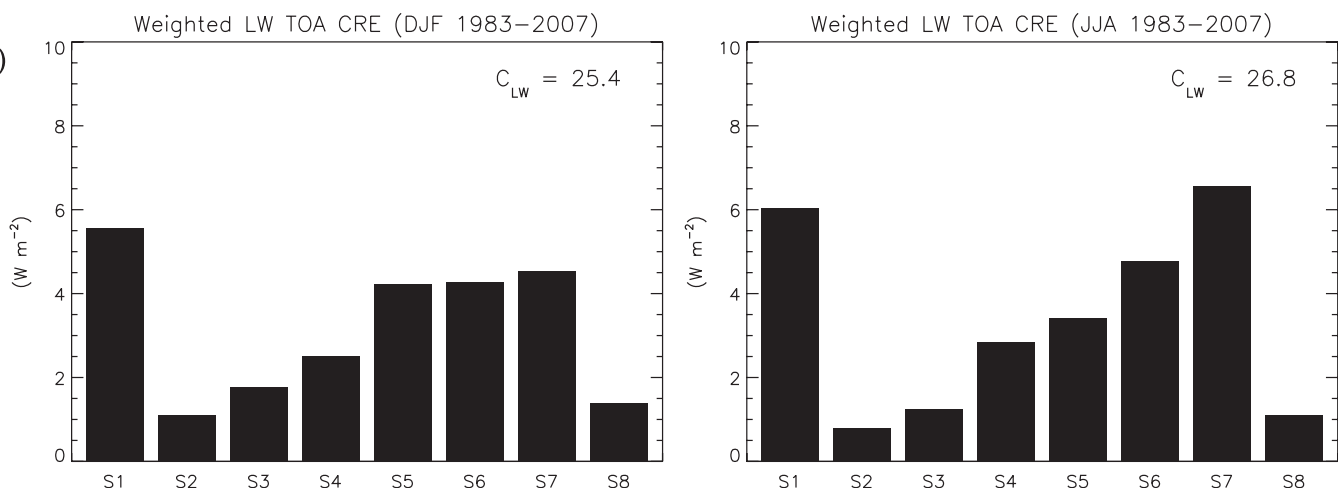

FIG. 14. As in Fig. 13, except showing cloud radiative effects weighted by regime FOCC. Total cloud radiative effect is also shown $\left(\mathrm{W} \mathrm{m}^{-2}\right)$.

are pre-cold frontal, or associated with the active portions of midlatitude cyclones, and others are post-cold frontal and occur in more benign environments. By partitioning the CloudSat-CALIPSO observations according to the simultaneously occurring ISCCP-defined cloud regime, we can examine the vertical structure of the cloud regimes directly, which is not possible from the passive instruments alone. The active sensors reveal that all of the regimes contain a relatively high occurrence of low cloud, with $79 \%$ of all cloud layers observed having tops below $3 \mathrm{~km}$, and that cloud systems are physically thicker, on average, during winter than during summer (despite a higher tropopause in summer). The incidence of precipitation within the ISCCP regimes is also examined. The regimes most closely associated with midlatitude cyclones produce precipitation (including the heaviest precipitation) the most frequently, although drizzle is extremely common in the low-cloud regimes.

The active sensors allow cloud structures to be examined in terms of the co-occurrence of cloud layers, resulting in the finding that many of the cloud systems ISCCP classifies as middle-top cloud actually consist of relatively thin mid-to-upper-level cloud layers with simultaneously occurring low-level cloud. In general, it is apparent that ISCCP tends to overestimate midlevel cloudiness, a finding that agrees with the surface radar observations of Tselioudis and Kollias (2007), which were collected over the Atmospheric Radiation Measurement Program (ARM) Southern Great Plains site. This phenomenon is not limited to the SHB or midlatitudes but extends into the tropics where multiplelayered systems are also ubiquitous (e.g., Haynes and Stephens 2007; Mace et al. 2011; Naud and Chen 2010).

In light of these findings, it is necessary to take account of the ISCCP overestimate of midlevel cloud amount for the SHB or anywhere else with frequent high-level, optically thin clouds overlying low-level clouds. Specifically, it is ill-conceived to compare ISCCP cloud tops directly with modeled cloud boundaries, since the former are based on an effective emission height of (possibly many) individual cloud layers while the latter are representative of physical cloud height. Second, even if one sidesteps this issue by utilizing the ISCCP simulator to reproduce what ISCCP would observe given a modeled cloud field (Klein and Jakob 1999), an affirmative match between the observed and simulated clouds would not necessarily indicate that the model was faithfully reproducing the cloud distribution of the real atmosphere. This is for reasons in addition to possible ISCCP biases in cloud optical depth identified by Mace et al. (2011). In those locations where mid-to-upper-level thin cloud 
frequently coexists with boundary layer cloud (as is often the case in the SHB), a model that overproduces cloud at midlevels could, for example, produce ISCCP simulator output that matched the ISCCP observations but not the physical cloud distribution that was present. Even a perfect simulator could not avoid this issue, which is why the additional information provided by active sensors, such as CloudSat-CALIPSO and the ARM surface radars, is so valuable. This study has demonstrated that cloud regimes are one useful way to connect these very different observational platforms, and model evaluation studies demonstrating the utility of this combination are currently under way.

Last, the TOA cloud shortwave and longwave cloud radiative effects are evaluated on a regime-by-regime basis. Shortwave cloud effects are found to dominate longwave cloud effects during the summer months but are of comparable magnitude during the winter months when the mean solar zenith angle is higher. Although the regimes associated with the active portions of cyclones have the highest shortwave CRE at the TOA when evaluated per regime, the low-cloud regimes, by virtue of their high frequency of occurrence over the oceans, dominate TOA shortwave effects in this region. We therefore speculate that low-cloud misrepresentation in climate models over the SHB may have a larger effect on the corresponding TOA energy balance errors than do model errors in the frequency of occurrence of frontal clouds associated with the active portions of midlatitude cyclones.

Acknowledgments. The research in this study is supported by the Australian Research Council's Linkage Project Scheme (LP0883961).

\section{REFERENCES}

Anderberg, M. R., 1973: Cluster Analysis for Applications. Academic Press, 359 pp.

Bates, T. S., B. J. Huebert, J. L. Gras, F. B. Griffiths, and P. A. Durkee, 1998: International Global Atmospheric Chemistry (IGAC) project's first Aerosol Characterization Experiment (ACE 1): Overview. J. Geophys. Res., 103, 16 297-16 318.

Boers, R., and P. B. Krummel, 1998: Microphysical properties of boundary layer clouds over the Southern Ocean during ACE 1. J. Geophys. Res., 103, 16 651-16 663.

Brown, J. R., C. Jakob, and J. M. Haynes, 2010: Rainfall frequency and intensity over Australia and their association with the atmospheric circulation in a global climate model. J. Climate, 23, 6504-6525.

Ellis, T. D., T. L'Ecuyer, J. M. Haynes, and G. L. Stephens, 2009: How often does it rain over the global oceans? The perspective from CloudSat. Geophys. Res. Lett., 36, L03815, doi:10.1029/ 2008GL036728.

Fitzpatrick, M. F., and S. G. Warren, 2007: The relative importance of clouds and sea ice for the solar energy budget of the Southern Ocean. J. Climate, 20, 941-954.
Gordon, N. D., and J. R. Norris, 2010: Cluster analysis of midlatitude oceanic cloud regimes: Mean properties and temperature sensitivity. Atmos. Chem. Phys., 10, 6435-6459, doi:10.5194/acp-10-6435-2010.

Hagihara, Y., H. Okamoto, and R. Yoshida, 2010: Development of a combined CloudSat-CALIPSO cloud mask to show global cloud distribution. J. Geophys. Res., 115, D00H33, doi:10.1029/ 2009JD012344.

Harrison, E. F., P. Minnis, B. R. Barkstrom, V. Ramanathan, R. D. Cess, and G. G. Gibson, 1990: Seasonal variation of cloud radiative forcing derived from the Earth Radiation Budget Experiment. J. Geophys. Res., 95, 18 687-18 703.

Haynes, J. M., and G. L. Stephens, 2007: Tropical oceanic cloudiness and the incidence of precipitation: Early results from CloudSat. Geophys. Res. Lett., 34, L09811, doi:10.1029/ 2007 GL029335.

, T. S. L'Ecuyer, G. L. Stephens, S. D. Miller, C. Mitrescu, N. B. Wood, and S. Tanelli, 2009: Rainfall retrieval over the ocean with spaceborne W-band radar. J. Geophys. Res., 114, D00A22, doi:10.1029/2008JD009973.

Jakob, C., and G. Tselioudis, 2003: Objective identification of cloud regimes in the tropical western Pacific. Geophys. Res. Lett., 30, 2082, doi:10.1029/2003GL018367.

,-- , and T. Hume, 2005: The radiative, cloud, and thermodynamic properties of the major tropical western Pacific cloud regimes. J. Climate, 18, 1203-1215.

Jin, Y., and W. B. Rossow, 1997: Detection of cirrus overlapping low-level clouds. J. Geophys. Res., 102, 1727-1737.

$\longrightarrow,-$, and D. P. Wylie, 1996: Comparison of the climatologies of high-level clouds from HIRS and ISCCP. J. Climate, 9, 2850-2879.

Kanamitsu, M., W. Ebisuzaki, J. Woollen, S.-K. Yang, J. J. Hnilo, M. Fiorino, and G. L. Potter, 2002: NCEP-DOE AMIP-II Reanalysis (R-2). Bull. Amer. Meteor. Soc., 83, 1631-1643.

Klein, S. A., and C. Jakob, 1999: Validation and sensitivities of frontal clouds simulated by the ECMWF model. Mon. Wea. Rev., 127, 2514-2531.

L'Ecuyer, T. S., N. B. Wood, T. Haladay, G. L. Stephens, and P. W. Stackhouse Jr., 2008: Impact of clouds on atmospheric heating based on the R04 CloudSat fluxes and heating rates data set. J. Geophys. Res., 113, D00A15, doi:10.1029/2008JD009951.

Liao, X. H., W. B. Rossow, and D. Rind, 1995: Comparison between SAGE-II and ISCCP high-level clouds. Part II: Locating cloud tops. J. Geophys. Res., 100, 1137-1147.

Liu, Z., M. A. Vaughan, D. M. Winker, C. A. Hostetler, L. R. Poole, D. Hlavka, W. Hart, and M. McGill, 2004: Use of probability distribution functions for discriminating between cloud and aerosol in lidar backscatter data. J. Geophys. Res., 109, D15202, doi:10.1029/2004jd004732.

Mace, G. G., Q. Zhang, M. Vaughan, R. Marchand, G. Stephens, C. Trepte, and D. Winker, 2009: A description of hydrometeor layer occurrence statistics derived from the first year of merged CloudSat and CALIPSO data. J. Geophys. Res., 114, D00A26, doi:10.1029/2007JD009755.

— S. Houser, S. Benson, S. A. Klein, and Q. Min, 2011: Critical evaluation of the ISCCP simulator using ground-based remote sensing data. J. Climate, 24, 1598-1612.

Marchand, R., G. G. Mace, T. Ackerman, and G. Stephens, 2008: Hydrometeor detection using Cloudsat-An Earth-orbiting 94-GHz cloud radar. J. Atmos. Oceanic Technol., 25, 519-533.

_ J. Haynes, G. G. Mace, T. Ackerman, and G. Stephens, 2009: A comparison of simulated cloud radar output from the multiscale modeling framework global climate model with 
CloudSat cloud radar observations. J. Geophys. Res., 114, D00A20, doi:10.1029/2008JD009790.

McAvaney, B. J., and H. Le Treut, 2003: The Cloud Feedback Intercomparison Project: CFMIP. CLIVAR Exchanges, No. 26 (Suppl.), International CLIVAR Project Office, United Kingdom, 1-4.

Meehl, G. A., C. Covey, K. E. Taylor, T. Delworth, R. J. Stouffer, M. Latif, B. McAvaney, and J. F. B. Mitchell, 2007: The WCRP CMIP3 multimodel dataset: A new era in climate change research. Bull. Amer. Meteor. Soc., 88, 1383-1394.

Morrison, A. E., S. T. Siems, M. J. Manton, and A. Nazarov, 2009: On the analysis of a cloud seeding dataset over Tasmania. J. Appl. Meteor. Climatol., 48, 1267-1280.

Naud, C. M., and Y.-H. Chen, 2010: Assessment of ISCCP cloudiness over the Tibetan Plateau using CloudSat-CALIPSO. J. Geophys. Res., 115, D10203, doi:10.1029/2009JD013053.

—, A. D. Del Genio, M. Bauer, and W. Kovari, 2010: Cloud vertical distribution across warm and cold fronts in CloudSatCALIPSO data and a general circulation model. J. Climate, 23, 3397-3415.

Posselt, D. J., G. L. Stephens, and M. Miller, 2008: CloudSat: Adding a new dimension to a classical view of extratropical cyclones. Bull. Amer. Meteor. Soc., 89, 599-609.

Rossow, W. B., and R. A. Schiffer, 1991: ISCCP cloud data products. Bull. Amer. Meteor. Soc., 72, 2-20.

—, and — 1999: Advances in understanding clouds from ISCCP. Bull. Amer. Meteor. Soc., 80, 2261-2287.

— , and Y. Zhang, 2010: Evaluation of a statistical model of cloud vertical structure using combined CloudSat and CALIPSO cloud layer profiles. J. Climate, 23, 6641-6653.

— G. Tselioudis, A. Polak, and C. Jakob, 2005: Tropical climate described as a distribution of weather states indicated by distinct mesoscale cloud property mixtures. Geophys. Res. Lett., 32, L21812, doi:10.1029/2005GL024584.

Simmonds, I., and K. Keay, 2000: Mean Southern Hemisphere extratropical cyclone behavior in the 40-year NCEP-NCAR reanalysis. J. Climate, 13, 873-885.

Simmons, A. J., S. M. Uppala, D. P. Dee, and S. Kobayashi, 2006: ERA-Interim: New ECMWF reanalysis products from 1989 onwards. ECMWF Newsletter, No. 110, ECMWF, Reading, United Kingdom, 25-35.

Smith, E. J., L. G. Veitch, D. E. Shaw, and A. J. Miller, 1979: A cloudseeding experiment in Tasmania. J. Appl. Meteor., 18, 804-815.

Stephens, G. L., and Coauthors, 2008: CloudSat mission: Performance and early science after the first year of operation. J. Geophys. Res., 113, D00A18, doi:10.1029/2008JD009982.

Stubenrauch, C. J., W. B. Rossow, F. Cheruy, A. Chedin, and N. A. Scott, 1999: Clouds as seen by satellite sounders (3I) and imagers (ISCCP). Part I: Evaluation of cloud parameters. J. Climate, 12, 2189-2213.
Sun, Y., S. Solomon, A. G. Dai, and R. W. Portmann, 2006: How often does it rain? J. Climate, 19, 916-934.

Tanelli, S., and Coauthors, 2008: CloudSat's cloud profiling radar after two years in orbit: Performance, calibration, and processing. IEEE Trans. Geosci. Remote Sens., 46, 35603573.

Trenberth, K. E., and J. T. Fasullo, 2010: Simulation of present-day and twenty-first-century energy budgets of the southern oceans. J. Climate, 23, 440-454.

Tselioudis, G., and C. Jakob, 2002: Evaluation of midlatitude cloud properties in a weather and a climate model: Dependence on dynamic regime and spatial resolution. J. Geophys. Res., 107, 4781, doi:10.1029/2002jd002259.

- and P. Kollias, 2007: Evaluation of ECMWF cloud type simulations at the ARM Southern Great Plains site using a new cloud type climatology. Geophys. Res. Lett., 34, L03803, doi:10.1029/2006GL027314.

_ , Y. C. Zhang, and W. B. Rossow, 2000: Cloud and radiation variations associated with northern midlatitude low and high sea level pressure regimes. J. Climate, 13, 312-327.

Tsushima, Y., and Coauthors, 2006: Importance of the mixed-phase cloud distribution in the control climate for assessing the response of clouds to carbon dioxide increase: A multi-model study. Climate Dyn., 27, 113-126.

Walsh, J. E., W. L. Chapman, and D. H. Portis, 2009: Arctic cloud fraction and radiative fluxes in atmospheric reanalyses. J. Climate, 22, 2316-2334.

Warren, S. G., C. J. Hahn, J. London, R. M. Chervin, and R. L. Jenne, 1986: Global distribution of total cloud cover and cloud type amounts over the ocean. NCAR Tech. Note NCAR/TN273+STR, 41 pp.

Williams, K. D., and G. Tselioudis, 2007: GCM intercomparison of global cloud regimes: Present-day evaluation and climate change response. Climate Dyn., 29, 231-250.

Winker, D. M., W. H. Hunt, and M. J. McGill, 2007: Initial performance assessment of CALIOP. Geophys. Res. Lett., 34, L19803, doi:10.1029/2007GL030135.

Wu, J., M. Zhang, and W. Lin, 2007: A case study of a frontal system simulated by a climate model: Clouds and radiation. J. Geophys. Res., 112, D12201, doi:10.1029/2006jd008238.

Zhang, M. H., and Coauthors, 2005: Comparing clouds and their seasonal variations in 10 atmospheric general circulation models with satellite measurements. J. Geophys. Res., 110, D15S02, doi:10.1029/2004JD005021.

Zhang, Y., W. B. Rossow, A. A. Lacis, V. Oinas, and M. I. Mishchenko, 2004: Calculation of radiative fluxes from the surface to top of atmosphere based on ISCCP and other global data sets: Refinements of the radiative transfer model and the input data. J. Geophys. Res., 109, D19105, doi:10.1029/ 2003JD004457. 